\title{
Human Neural Stem Cells Differentiate and Integrate, Innervating Implanted zQ175
}

\section{Huntington's Disease Mouse Striatum}

$9{ }^{1}$ Intellectual and Developmental Disabilities Research Center, Semel Institute for Neuroscience

10 \& Human Behavior, David Geffen School of Medicine, University of California Los Angeles,

11 Los Angeles, CA, ${ }^{2}$ Institute for Memory Impairment and Neurological Disorders, University of

12 California Irvine, Irvine CA, ${ }^{3}$ Department of Psychiatry \& Human Behavior, University of

13 California Irvine, Irvine CA, ${ }^{4}$ Portland VA Medical Center, Portland, OR, ${ }^{5}$ Institute for

14 Regenerative Cures University of California Davis, Sacramento, CA, ${ }^{6}$ Department of Pathology

15 \& Laboratory Medicine, University of California, Irvine, Irvine, CA, ${ }^{7}$ Sue and Bill Gross Stem

16 Cell Center University of California Irvine, Irvine, $\mathrm{CA}^{8}$ Oregon Health \& Science University,

17 Department of Behavioral Neuroscience and Pathology, Portland, OR, ${ }^{9}$ Brain Research Institute,

18 David Geffen School of Medicine, University of California Los Angeles, Los Angeles, CA,

$19{ }^{10}$ Department of Neurobiology \& Behavior University of California Irvine, Irvine CA,

$20 †$ Co-first authors

$21{ }^{\wedge}$ Co-senior authors

$22 *$ To whom correspondence should be addressed: Leslie M. Thompson, University of California,

23 Irvine, Irvine, CA 92697, USA. Telephone: (949) 824-6756; Email: $\underline{\text { mthomps@uci.edu }}$ 


\section{Abstract}

25 Huntington's disease (HD), a genetic neurodegenerative disorder, primarily impacts the striatum

26 and cortex with progressive loss of medium-sized spiny neurons (MSNs) and pyramidal neurons,

27 disrupting cortico-striatal circuitry. A promising regenerative therapeutic strategy of transplanting

28 human neural stem cells (hNSCs) is challenged by the need for long-term functional integration.

29 We previously described that hNSCs transplanted into the striatum of HD mouse models

30 differentiated into electrophysiologically active immature neurons, improving behavior and

31 biochemical deficits. Here we show that 8-month implantation of hNSCs into the striatum of

32 zQ175 HD mice ameliorates behavioral deficits, increases brain-derived neurotrophic factor

33 (BDNF) and reduces mutant Huntingtin (mHTT) accumulation. Patch clamp recordings,

34 immunohistochemistry and electron microscopy demonstrates that hNSCs differentiate into

35 diverse neuronal populations, including MSN- and interneuron-like cells. Remarkably, hNSCs

36 receive synaptic inputs, innervate host neurons, and improve membrane and synaptic properties.

37 Overall, the findings support hNSC transplantation for further evaluation and clinical development

38 for HD.

\section{Introduction}

41 Huntington's disease (HD) is a devastating neurodegenerative disorder that typically strikes

42 individuals in midlife and progresses over 15-20 years before patients succumb to the disease

43 (Ghosh and Tabrizi, 2018). HD is caused by an autosomal dominant CAG (glutamine) repeat

44 expansion in the huntingtin (HTT) gene (The Huntington's Disease Collaborative Research Group,

45 1993). Symptoms include progressive movement abnormalities, most notably chorea, difficulties

46 with daily tasks, cognitive decline and psychiatric manifestations including depression, memory 
47 loss, and eventually dementia (Bates et al., 2002; Harper and Jones, 2002). Neuropathologically,

48 the disease substantially impacts the striatum and cerebral cortex, with progressive loss of

49 medium-sized spiny neurons (MSNs) and cortical pyramidal neurons, as well as loss of cortico-

50 striatal synapses, leading to severe atrophy (Vonsattel and DiFiglia, 1998; Waldvogel et al., 2015).

51 At the molecular level, the disease is accompanied by progressive loss of neuronal proteins,

52 including brain-derived neurotrophic factor (BDNF) that supports survival of striatal neurons, as

53 well as aberrant accumulation of aggregated huntingtin (HTT) protein species that correspond to

54 disease pathogenesis (Saudou and Humbert, 2016). There is currently no FDA approved disease

55 modifying treatments for HD patients that can either delay onset or modify disease progression.

56 Recent strategies that show promise include DNA-targeting techniques such as zinc-finger proteins

57 and CRISPR/Cas9, as well as HTT-lowering techniques currently in clinical trials, such as RNAi

58 and antisense oligonucleotides (Tabrizi et al., 2019). However, these strategies also have

59 limitations including efficient and targeted delivery, as well as the inability to replace or

60 compensate for neuronal loss. Thus, there is an urgent need to finding additional therapeutic

61 approaches.

62 In recent years, there has been an explosion of studies in regenerative medicine. The use

63 of neural stem cells (NSCs) for the treatment of neurological disorders is in the early stages but

64 there is already a wealth of information indicating that NSCs may offer a viable therapeutic avenue

65 (El-Akabawy et al., 2012; Choi and Hong, 2017; Connor, 2018). We recently demonstrated that

66 human (h)NSCs implanted in the striatum of R6/2 mice, a severe and rapidly progressing model

67 of HD akin to juvenile HD (Mangiarini et al., 1996), survive, are functional, and improve a number

68 of HD phenotypes (Holley et al., 2018; Reidling et al., 2018). Studies also included the long-lived

69 full-length homozygous Q140 HD mouse model and we showed behavioral improvements and 
70 reduced aggregation; however, characterization of cells was limited due to low cell survival rate,

71 perhaps caused by insufficient immunosuppression methods. Therefore, in the present study, we

72 determined whether hNSCs can survive for longer periods of time, the types of cells they

73 differentiate into in the host brain, whether cells are electrophysiologically active, whether they

74 make connections with host cells and if neuroprotective effects persist. For these purposes, we

75 used the heterozygous zQ175 mouse model that recapitulates aspects of adult-onset HD (Menalled

76 et al., 2012). Heterozygous mice do not show overt behavioral symptoms until approximately 6

77 months of age and become fully symptomatic at 8-12 months (Heikkinen et al., 2012).

78 Electrophysiological studies have demonstrated altered passive and active membrane properties of

79 MSNs in symptomatic animals, as well as changes in synaptic activity (Heikkinen et al., 2012;

80 Plotkin et al., 2014; Indersmitten et al., 2015; Southwell et al., 2016; Sepers et al., 2018). These

81 functional alterations are associated with significant loss of neuron spines. Here we tested the

82 viability, morphological and electrophysiological properties of hNSCs, as well as their potential

83 therapeutic benefits in zQ175 mice. hNSCs were implanted in the striatum of pre-symptomatic

84 mice (2.5 months), behavioral tests were performed for 8 months, electrophysiological tests began

85 when the mice became fully symptomatic (10.5 months of age) and tissue was collected for

86 immunohistochemical, biochemical, and morphological analyses. Our data show that implanted

87 hNSCs survive, and a subset differentiate into mature MSNs and interneurons, establish

88 connections with the host neurons, and rescue specific electrophysiological and behavioral

89 phenotypes.

90

91

92 


\section{Results}

94 ESI-017 hNSCs Transplanted Long-Term in zQ175 HD Model Mice Engraft and

95 Differentiate: Our previous studies showed beneficial effects of hNSC implantation in R6/2 and

96 Q140 model mice (Holley et al., 2018; Reidling et al., 2018). Here we wished to comprehensively

97 evaluate whether hNSCs could survive for extended periods of time, whether they could further

98 differentiate, and whether they could functionally compensate for loss of connectivity and neuronal

99 function, which has not yet been described in a genetic model of HD. GMP-grade ESI-017 hNSCs

100 (Holley et al., 2018; Reidling et al., 2018) were acquired as frozen aliquots (UC Davis), thawed,

101 and cultured without passaging using the same media reagents as in the GMP facility. Mice were

102 dosed by intrastriatal stereotactic delivery of 100,000 hNSCs per hemisphere at 2.5 months of age.

103 To examine long-term survival of hNSCs, zQ175 mice were sacrificed at 10.5 months of age (8

104 months post-implant). The fate of the implanted cells was determined using IHC with markers for

105 human cells, neural progenitor cells, post-mitotic neurons, astrocytes and oligodendrocytes.

106 Implanted ESI-017 hNSCs survived and remained in the striatum with little migration away from

107 the needle tract in most mice. When proliferative hNSCs are implanted into mice they are non-

108 proliferative 8 months post-implant as indicated by a lack of staining for the proliferation marker

109 Ki67 or when analyzed for the incorporation of the nucleotide analog EdU (Fig. 1A \& B).

110 Implanted hNSCs also did not express the neural stem cell marker nestin (Fig. 1C), supporting

111 that they have differentiated. A survey of cell markers revealed that the implanted hNSCs

112 differentiated into previously observed lineages of immature neurons (doublecortin, DCX+, Fig.

113 1D \& E), very few astrocytes (glial fibrillary acidic protein, GFAP+, Fig. 1C), but not

114 oligodendrocytes. Some cells appeared to differentiate into mature neurons (neuronal nuclei,

115 NeuN+, Fig. 1D, E \& I and BetaIII tubulin+, Fig. 1G) or interneurons (calretinin, CR+, Fig. 1F, 
116 or glutamic acid decarboxylase 65/67, Gad65/67+, Fig. 1G). We also detected glutamate

117 transporter, vGlut1+ puncta surrounding implants potentially from cortical terminals (Fig. 1F).

118 hNSCs also differentiated into MSNs (dopamine- and cAMP-regulated neuronal phosphoprotein,

119 DARPP32+ and B-cell lymphoma/leukemia 11B, Ctip2+ Fig. 1H, I \& J). In addition, there is

120 evidence that some hNSCs differentiated into cell types that exhibit inhibitory neuronal signals

121 (gamma-aminobutyric acid, GABA+ Fig. 1J). These longer duration survival studies suggest that, 122 given enough time, the hNSCs are no longer proliferative and can differentiate into post-mitotic 123 neurons typically found in striatum.

124 After analysis of multiple brain sections, we observed evidence of some cell migration on

125 the white matter tracts between the striatum and cortex $(\sim 50 \%$ of the zQ175 but only a few WT 126 mice). In addition, a subset of these mice that displayed cell migration ( $\sim 30 \%$ overall of implanted 127 mice) exhibited nodules of cells that were positive for the human marker Ku80 adjacent to the cells 128 in the implant site and in the ventricular space, but not in the striatum. H\&E stains on adjacent 129 sections of tissue (Fig. 1K \& L) were performed and cytologically the cells in the nodules appeared 130 to be mostly well-differentiated, mature-looking neurons. No evidence of proliferation was 131 observed using Ki67 and nestin staining, suggesting these nodules are not a cause of concern in 132 terms of potential for being or forming metastatic tumors. We performed IHC on another cohort 133 of zQ175 and WT mice at 1, 2 and 5 months post implant in an attempt to observe the formation 134 of nodules over time but did not observe any nodule formation. Between implantation of the 135 original cohort and the nodule test mice we made a minor improvement to the surgical apparatus 136 that may have altered hNSC migration on white matter tracks. 


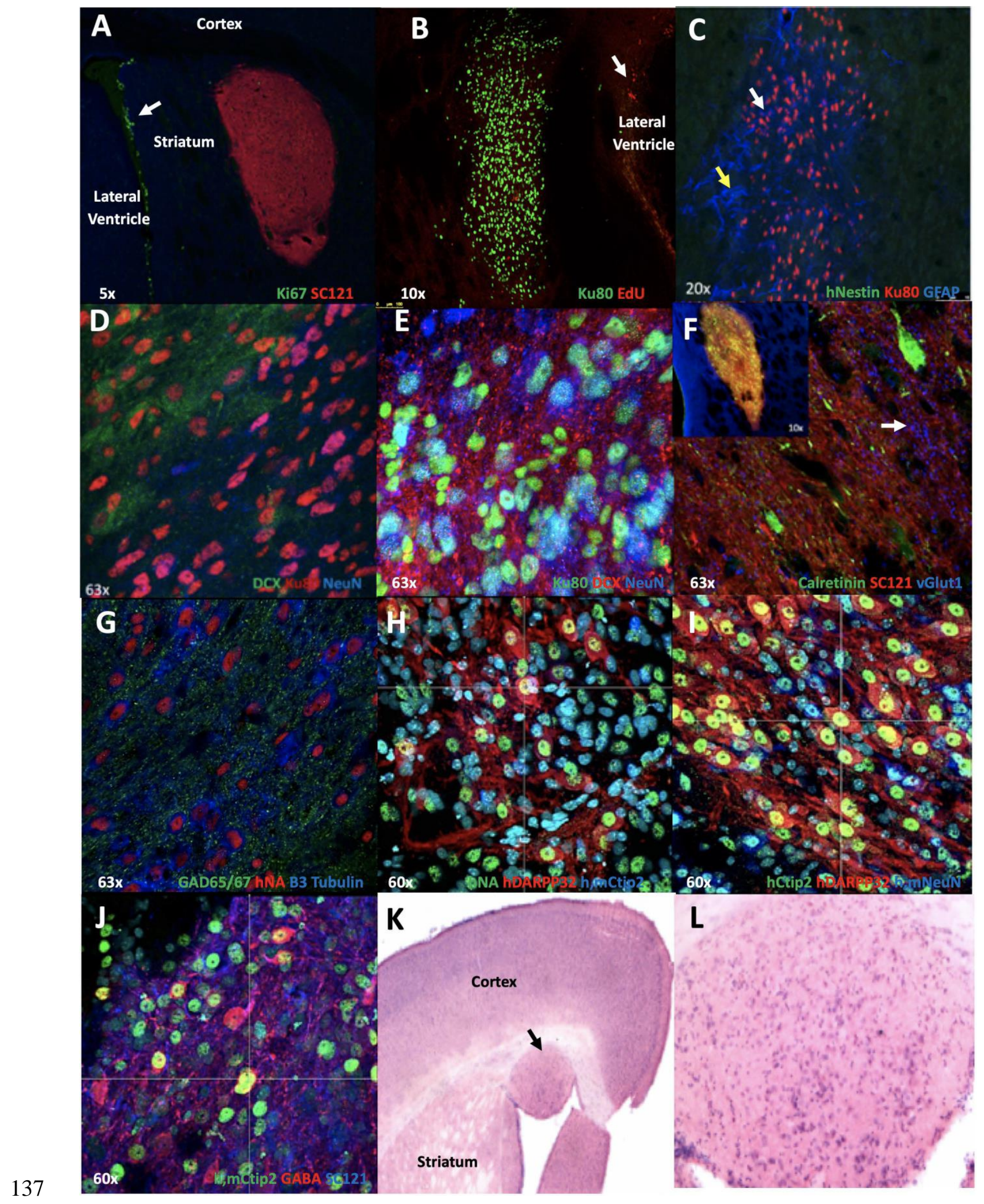



5x mag. hNSCs (human cytosolic marker SC121, red) in zQ175 mice do not express the proliferation marker Ki67 (green). Proliferating cells in the lateral ventricle are indicated by arrow. B) $10 \mathrm{X}$ mag. showing hNSCs (human nuclear marker Ku80, green) did not incorporate the nucleotide analog EdU $24 \mathrm{hrs}$ post injection indicating they are not dividing. C) 20x shows hNSCs (Ku80, red) do not express the neuronal progenitor marker nestin (green) but some cells show expression of the astrocyte marker GFAP (blue, white arrow). The hNSC implant site is surrounded by a mouse glial cell scar (GFAP+ blue, yellow arrow). D) hNSCs (Ku80, red) differentiate into both immature DCX+ (green) and more mature (NeuN, blue) neurons, shown at 63x. E) Another image of hNSCs (Ku80, green) differentiating into both immature DCX+ (red) and more mature (NeuN, blue) neurons, shown at 63x. F) 63x mag. hNSCs (SC121, red) differentiate into interneurons Calretinin (green) and some vGlut1 (blue, white arrow) puncta can be observed in the implantation site. The inset image shows the entire implant at 10x. G) 63x mag. hNSCs (Human nuclear antigen HNA, red) differentiate into a mixed population of cells that costain with GAD65/67 (green) or Beta III-tubulin (blue). H) Image shows hNSCs (HNA, green) differentiating into MSNs, DARPP32+ (red) Ctip2+ (blue) at 60x. I) Another 60x image showing hNSCs differentiating into MSNs using hDARPP32+ (red) and hCtip2+ (blue) only, as well as some other hNSCs expressing the mature neuronal marker NeuN. J) 60x image shows hNSCs (SC121, blue) expressing the MSN marker Ctip2 (green) and co-localization with the inhibitory neuronal marker GABA (red). K) 4x mag. and L (20x) showing H\&E stains. A small nodule of cells that migrated away from the initial injection track are shown (at arrow, enlarged in L). Review from pathology included the comments that cytologically, the cells in the nodules are mostly well differentiated cells, with lots of large, mature-looking neurons.

ESI-017 hNSCs Improve Behavior in zQ175 HD Mice: We previously established that homozygous Q140 HD model mice (Reidling et al., 2018). To determine if hNSC implantation

167 behavioral assays for these mice. We found strikingly significant improvements in the running

168 wheel test in mice that were 7.5 months old (5.5 months post implant) in ESI-017 hNSC implanted

169 heterozygous zQ175 mice compared to vehicle mice, suggesting a reversion to WT levels and

170 persistence of the effect (Fig. 2A). The slope of motor learning was not significantly different

171 among the 3 groups. In addition, we found significant improvements in distance traveled and

172 velocity for hNSC-treated male and female mice combined compared to vehicle in the open field 
173 in mice that were 8 months of age (6 months post-implant) (Fig. 2B \& C). All open field behavioral

174 outcomes are provided in Supplementary Materials (Suppl. Fig. 1A-C).

176 Engrafted ESI-017 hNSCs Correlate with Increased BDNF and Decreased Pathogenic

177 Accumulation of mHTT Proteins: Increased levels of BDNF were demonstrated after hNSC

178 implantation in the rapidly progressing R6/2 HD mouse model (Reidling et al., 2018), therefore

179 we evaluated whether this effect could be sustained following long-term engraftment in zQ175

180 mice. Striatal BDNF quantified by Western blot analysis was slightly but not significantly

181 decreased in a subset of male zQ175 mice (n=3/group) compared to WT, but a significant increase

182 in BDNF levels was observed in hNSC-treated zQ175 mice compared to vehicle (Fig. 2D \& E).

183 Interestingly, we also observed an increase in the phosphorylation of extracellular signal-regulated

184 kinase (ERK) protein suggesting potential activation of cellular signaling cascades (Fig. 2D \& F).

185 In addition, our previous studies showed that hNSC treatment can reduce high molecular weight

186 (HMW) mHTT species, a pathogenic marker for HD. Consistent with those results we also

187 observed persistent reduction in levels of a HMW mHTT species in hNSC treated zQ175 mice

188 (Fig. 2G \& H), suggesting prevention of pathology by the transplanted cells. 

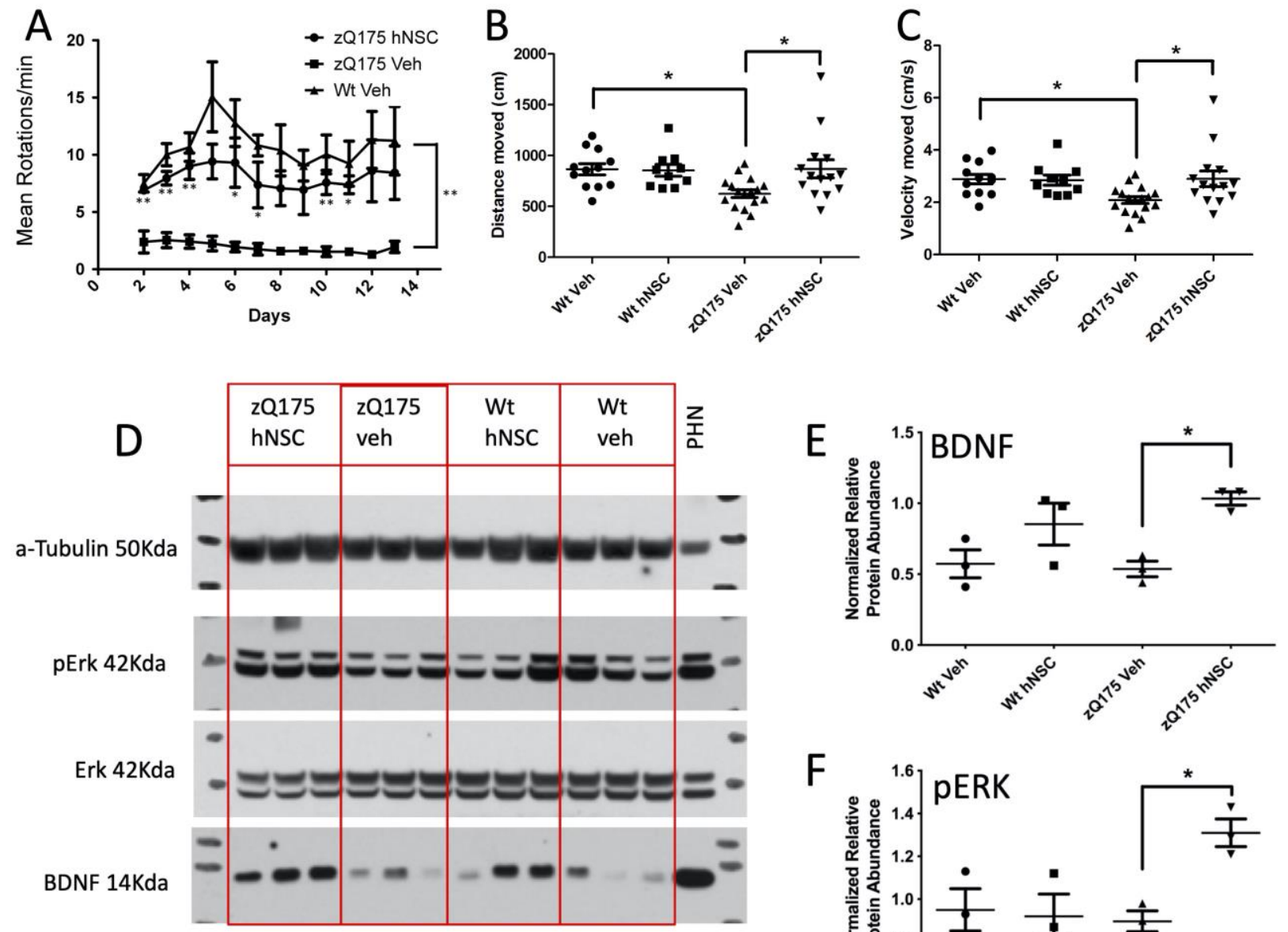

F
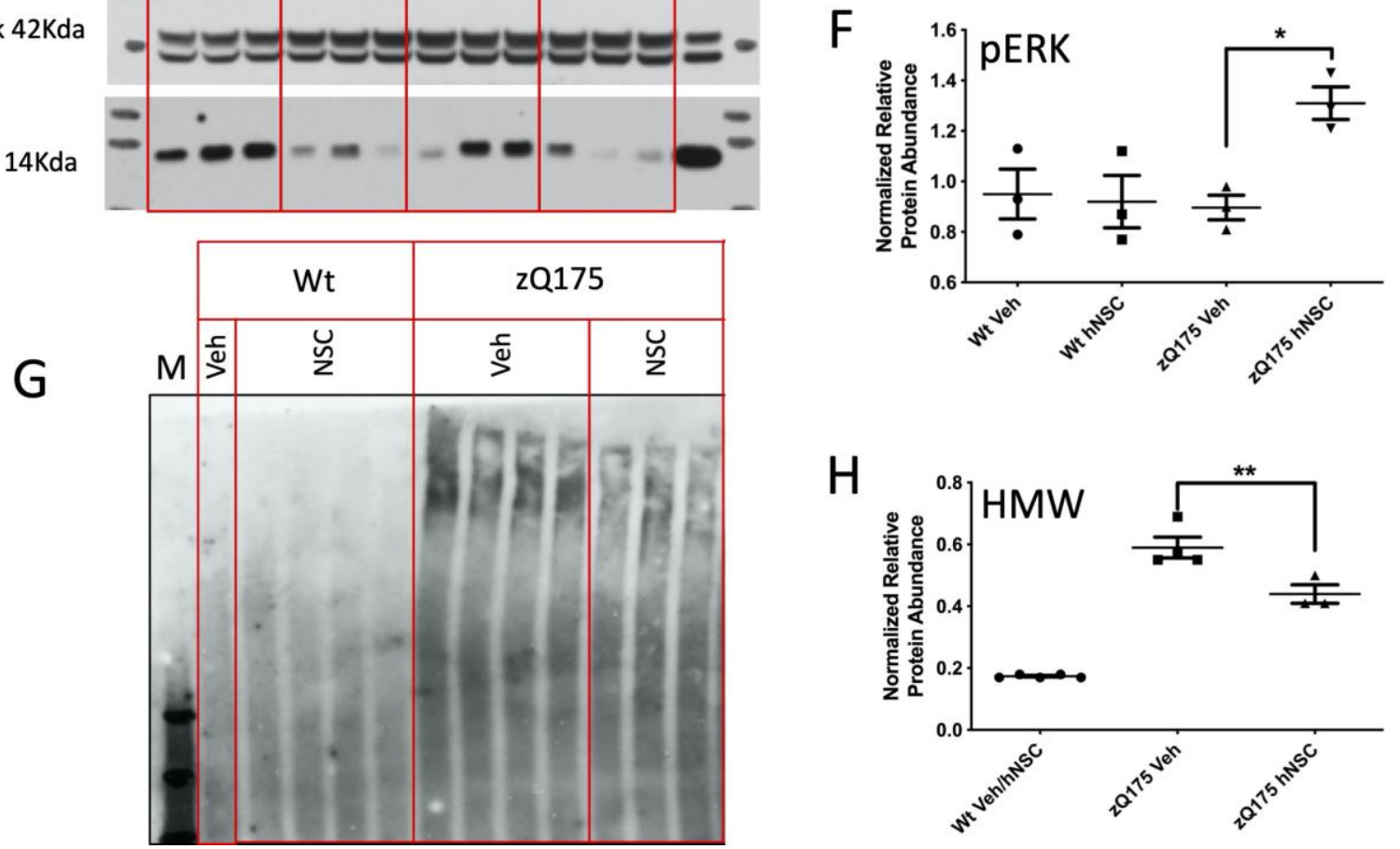

190 Figure 2: ESI-017 hNSCs implanted in zQ175 mice improve behavior, increase BDNF and 191 p-ERK levels and reduce levels of a HMW mHTT species: A. Running wheel shows persistent 192 improvement 5.5 months post-treatment. Mean running wheel rotations/minute/night over two 193 weeks, in WT, zQ175 vehicle (veh) treated or zQ175 hNSC and zQ175 veh treated male mice 194 (5/group). Results are expressed as the mean \pm S.E.M one-way ANOVA Tukey HSD and 195 Bonferroni post test $\mathrm{p}$ values for $\mathrm{zQ} 175$ veh treated to $\mathrm{zQ175}$ hNSC treated Day2=0.003 
Day3 $=0.001$, Day4=0.002, Day5=0.06, Day6=0.03, Day7=0.03, Day $8=0.07$, Day9=0.06, Day10 $=0.009$, Day11 $=0.01$, Day12 $=0.08$, Day13 $=0.1$ summarized as $* \mathrm{p}<0.05$, $* * \mathrm{p}<0.01$, shown below error bars. WT veh to zQ175 veh Day2 $=0.001$ Day3 $=0.001$, Day4 $=0.001$, Day5 $=0.002$, Day6 $=0.002$, Day7 $=0.001$, Day8 $=0.005$, Day9 $=0.01$, Day $10=0.001$, Day $11=0.002$, Day $12=0.02$, Day13 $=0.03$, summarized as $* * p \leq 0.03$ at right. WT veh to zQ175 hNSC was not significantly different at any time-point. B. Total distance traveled in the open field 6 months post implant. Mice were subjected to the open field and total distance in centimeters of their respective tracks were combined and statistically analyzed to visualize any differences in ambulation. The zQ175 veh treated mice traveled less distance than WT veh and zQ175 hNSC treated mice. C. Velocity traveled in the open field 6 months post implant. Mice were subjected to the open field and velocity traveled in centimeters/sec of their respective tracks were combined and statistically analyzed to visualize any differences in time of ambulation. The zQ175 veh treated mice traveled slower than WT veh and zQ175 hNSC treated mice. Groups for open field included: 7 male zQ175 Het hNSC, 7 female Het hNSC, 9 male zQ175 Het veh, 8 female zQ175 Het veh, 5 male WT hNSC, 5 female WT hNSC, 6 male WT veh, 6 female WT veh. Results are expressed as the mean \pm S.E.M with one-way ANOVA Tukey HSD and Bonferroni post test: * $\mathrm{p}=0.03$ for genotype and $\mathrm{p}=0.02$ for hNSC treatment in zQ175. D. Western blot analysis of whole tissue mouse striatal lysates from zQ175 and WT mice. zQ175 mice exhibited non-significantly reduced levels of BDNF compared to WT mice and levels were significantly increased with hNSC treatment. zQ175 mice also showed significantly increased levels of pERK compared to vehicle controls. Quantitation of the relative protein expression for $\operatorname{BDNF}(\mathbf{E})$ and pERK $(\mathbf{F})$ is shown. G. Western blot analysis of mouse striatal lysates separated into detergent-soluble and detergent-insoluble fractions. zQ175 mouse striatum is enriched in insoluble accumulated mHTT compared to WT mice. hNSC implantation in zQ175 mice results in a significant reduction of insoluble HMW accumulated HTT. Quantitation of the relative protein expression for mHTT is shown in $(\mathbf{H})$ and hNSC implantation results in a significant decrease of insoluble HMW accumulated mHTT. Graph values represent means \pm SEM and Western blots were analyzed with ImageJ for quantification of BDNF (normalized to tubulin), ERK/pERK ratio or aggregate type/section. Data was analyzed by oneway ANOVA with Tukey HSD and Bonferroni post hoc test $(\mathrm{n}=3$ /group $){ }^{*} \mathrm{p}=0.03,{ }^{* *} \mathrm{p}=0.005$.

Electrophysiological and Morphological Characterization of hNSCs: hNSCs transplanted for

4 weeks in R6/2 mice showed properties of immature electrophysiologically active hNSCs

(Reidling et al., 2018), however, we did not know whether this could be sustained or improved in

long-term implanted mice. To perform electrophysiological studies we used a subset of female zQ175 and WT mice (10.5 month-old) implanted at UCI and shipped live to UCLA. The hNSC grafts in zQ175 mice were easily identifiable under IR-DIC microscopy (Fig. 3A1 \& A2). In

232 contrast to host tissue, which appeared darker due to myelin from fiber tracks, the graft appeared 
234 findings, most cells $(\sim 80 \%)$ within the graft sites were small $(<15 \mu \mathrm{m}$ in diameter $)$, round or

235 bipolar, and had few extended processes. These cells appeared to be visually similar to the

236 immature neuronal cell types previously recorded in R6/2 mice 4-6 weeks after implantation

237 (Holley et al., 2018; Reidling et al., 2018). We also observed a number of cells that were larger in

238 size (15-25 $\mu \mathrm{m}$ in diameter) with abundant and extensive processes that were visually different

239 from host MSNs. As immature-looking hNSCs were characterized extensively in our previous

240 publication, in the present study we focused our recordings on these larger, more mature-looking

241 cells. We found for all hNSC types, membrane properties were similar for cells recorded in either

242 zQ175 or WT mice and data from recorded hNSCs from both genotypes were pooled (Table IA,

243 Fig. 3C).

244 Recorded cells in the grafts appeared to differentiate into two groups, one population of

245 cells with immature-like electrophysiological properties and one population with more mature-like

246 properties. In total, $49 \mathrm{hNSCs}$ were recorded ( $\mathrm{n}=18$ in WT and 31 in zQ175 mice). The two groups

247 of hNSCs were separated based on whole-cell patch-clamp recordings in voltage clamp mode

248 measuring passive membrane properties (cell membrane capacitance, input resistance and decay

249 time constant), as well as $\mathrm{Na}^{+}$current amplitudes. Cells with low membrane capacitance

250 (mean \pm s.e., $18.6 \pm 2.7 \mathrm{pF})$, high input resistance $(847.3 \pm 269.9 \mathrm{M} \Omega)$, fast time constant $(0.51 \pm 0.08$

$251 \mathrm{~ms})$, and $\mathrm{Na}^{+}$current amplitude $<1 \mathrm{nA}$ were immature-looking hNSCs $(\mathrm{n}=9,3$ in WT and 6 in

252 zQ175 mice) (Fig. 3B1 \& C). A number of these cells did not display $\mathrm{Na}^{+}$currents and were

253 probably glial cells, e.g., astrocytes ( $\mathrm{n}=2$ in WT and 5 in zQ175 mice). In contrast, cells with high

254 membrane capacitance $(128.5 \pm 10.0 \mathrm{pF})$, medium-high input resistance $(625.1 \pm 64.6 \mathrm{M} \Omega)$, slower

255 time constant $(2.2 \pm 0.2 \mathrm{~ms})$, and $\mathrm{Na}^{+}$current amplitude $>1 \mathrm{nA}$ were mature-looking $\mathrm{hNSCs}(\mathrm{n}=40$,

25615 in WT and 25 in zQ175 mice, Fig. 3B2 \& C). 
bioRxiv preprint doi: https://doi.org/10.1101/2021 01.18.427078; this version posted January 19,2021 . The copyright holder for this preprint (which was not certified by peer review) is the author/funder, who has granted bioRxiv a license to display the preprint in perpetuity. It is made available under aCC-BY 4.0 International license.
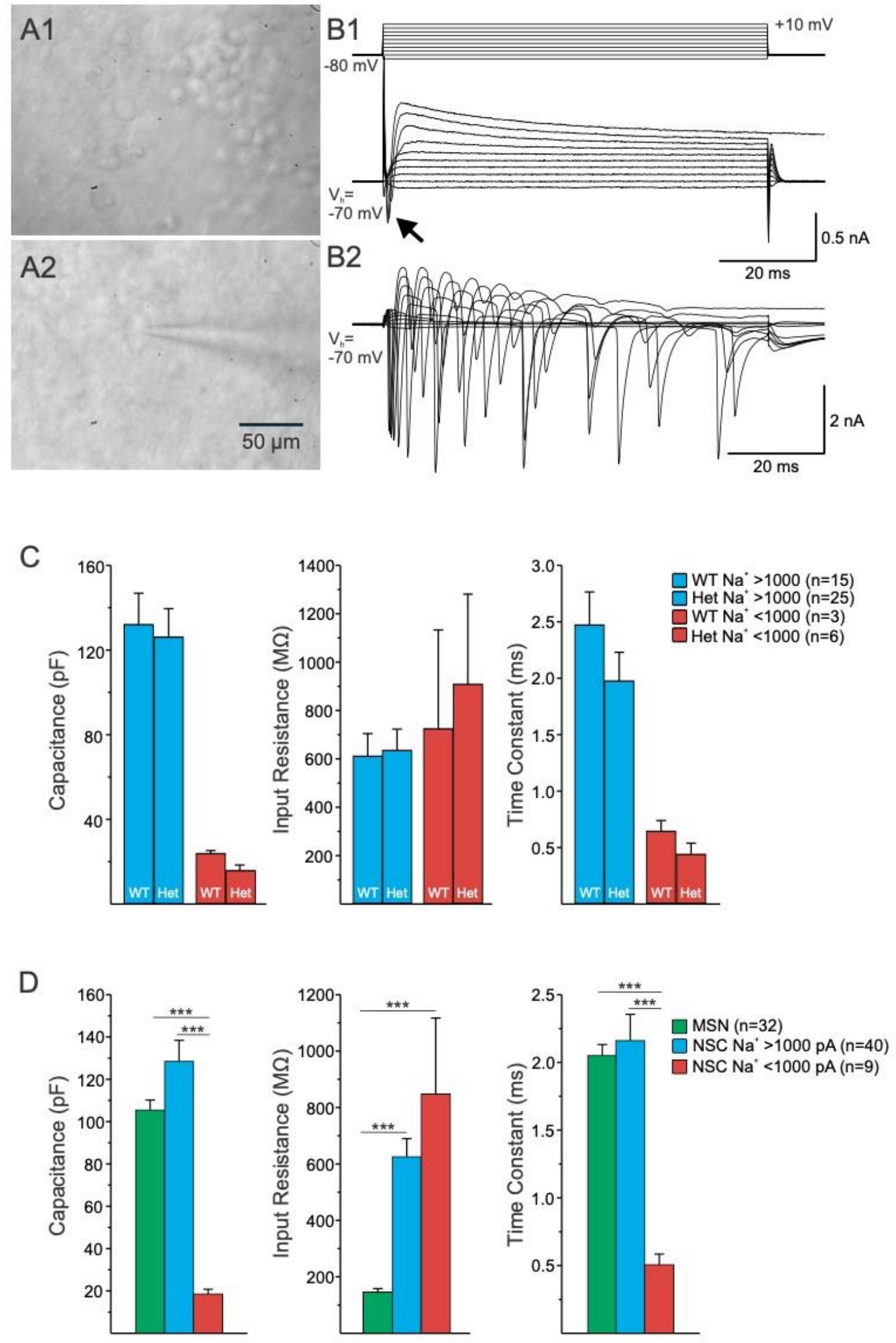
Figure 3: Two main types of hNSCs could be distinguished based on soma size, passive and active membrane properties. (A1). IR-DIC image from transplanted hNSCs in a zQ175 mouse revealed that most cells had small, round somata. (A2). A small percentage of hNSCs had larger somata and some dendritic branches. A patch pipette attached to the cell can be seen. Example cell is from a zQ175 mouse. (B1). Recordings performed on hNSCs in zQ175 mice show that depolarizing step voltage commands from a holding voltage $\left(V_{h}\right)$ of $-70 \mathrm{mV}$ induced only incipient $\mathrm{Na}^{+}$currents $(<1000 \mathrm{pA})$ and large outward $\mathrm{K}^{+}$currents. These cells were deemed immature. Example trace is from a zQ175 mouse. Voltage clamp protocol is shown above the current traces. (B2). Large cells displayed repetitive large $\mathrm{Na}^{+}$spikes $(>1000 \mathrm{pA})$ and were deemed mature. Example trace is from a WT mouse receiving an implant of hNSCs. C. Bar graphs show mean \pm S.E.M of cell membrane properties of two types of implanted hNSCs, those with immature (red) and those with mature (blue) membrane properties, using $\mathrm{Na}^{+}$current amplitude as cut-off. Capacitance, input resistance and time constants are shown for recorded hNSCs. D. Bar graphs show mean \pm S.E.M of cell membrane properties of host MSNs (WT and zQ175 pooled together) compared to implanted hNSCs. Capacitance, input resistance and time constants are shown for recorded host MSNs and mature and immature hNSCs. Statistical significance was measured using one-way ANOVA tests followed by Bonferroni post hoc tests for pairwise comparisons and *** represents $\mathrm{p}<0.001$. In (D.) Capacitance: $\mathrm{p}=2.0007 \mathrm{e}-05$ for MSN versus NSC Na+<1000 pA and $\mathrm{p}=6.1282 \mathrm{e}-08$ for NSC Na+>1000 pA versus NSC Na+<1000 pA. Input Resistance: $\mathrm{p}=5.3000 \mathrm{e}-$ 06 for MSN versus NSC Na+>1000 pA and $\mathrm{p}=2.6645 \mathrm{e}-05$ for MSN versus NSC Na+<1000 pA. Time Constant: $\mathrm{p}=8.9566 \mathrm{e}-05$ for MSN versus NSC Na+<1000 pA and $\mathrm{p}=1.7886 \mathrm{e}-05$ for NSC $\mathrm{Na}+>1000$ pA versus NSC Na+<1000 pA.

To further characterize maturation and differentiation of hNSCs, we compared their basic membrane properties with those of MSNs recorded from the host (Fig. 3D). While subtle

284 indirect pathways (Cepeda et al., 2008; Gertler et al., 2008), in the present study we did not capacitance, similar to or even larger than that of host MSNs. In contrast, cells with low amplitude $\mathrm{Na}^{+}$currents had very low membrane capacitance, similar to recordings from immature neurons. addition, differences in decay time constants were similar to those observed for cell capacitance. 
293 displayed inward $\mathrm{Ca}^{2+}$ currents. Some of these cells displayed $\mathrm{Ca}^{2+}$ currents larger in amplitude

294 and similar to those observed in host MSNs ( $n=5$ in WT mice and n=6 in zQ175) (Fig. 4).

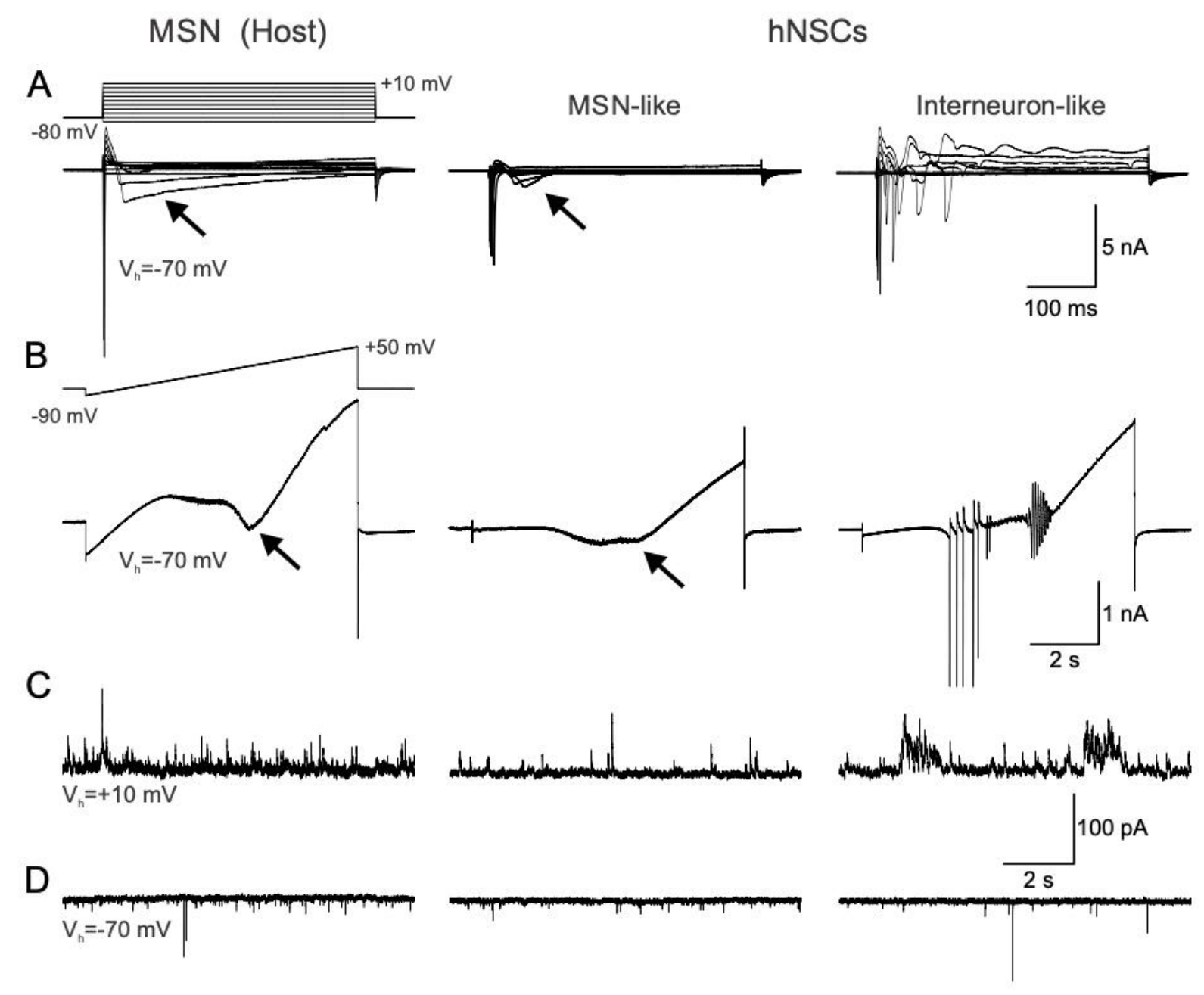

Figure 4: Examples of host MSN and mature hNSCs from a zQ175 mouse. Some hNSCs displayed mature neuronal properties that were similar to (MSN-like) and different (interneuronlike) from host MSNs. A. Recordings of intrinsic currents in response to step voltage commands (10 $\mathrm{mV}$ steps from -80 to $+10 \mathrm{mV}$ ) in a host MSN (left panel) and in a MSN-like (center panel) and an interneuron-like (right panel) hNSC. Depolarizing voltage commands induced large $\mathrm{Na}^{+}$ currents followed by inactivating $\mathrm{Ca}^{2+}$ currents (arrows) of variable amplitudes. In the interneuronlike cell, repetitive spikes were observed but no prominent $\mathrm{Ca}^{2+}$ currents. B. Recordings of currents in response to a ramp voltage command $(8 \mathrm{sec}$, from -90 to $+50 \mathrm{mV}$ ). Some hNSCs recorded (center panel) had properties similar to host MSNs, both displaying $\mathrm{Ca}^{2+}$ currents (black arrows) after membrane depolarization. Other large hNSCs recorded lacked $\mathrm{Ca}^{2+}$ currents but displayed repetitive $\mathrm{Na}^{+}$spikes (right panel) and were probably interneurons. C. Spontaneous synaptic currents recorded at $+10 \mathrm{mV}$ in a host MSN and in MSN-like and interneuron-like hNSCs. These 
currents are mostly GABAergic. D. Spontaneous synaptic currents recorded at $-70 \mathrm{mV}$ in a host MSN and in a MSN-like and an interneuron-like hNSC. These currents are most likely glutamatergic. Traces in each column are from the same cell. Calibrations on the right apply to all traces in each row.

The intrinsic membrane properties of these hNSCs were not significantly different regardless of the mouse genotype (Table IB \& C). These cells also displayed frequent spontaneous synaptic activity and could represent projection neurons with the potential to connect with other cells inside and outside the graft. Biocytin labeling revealed these cells had abundant dendritic processes and sparse spines (Fig. 5).

\section{Table I}

\section{A: Numbers and Percentages of hNSCs Recorded Electrophysiologically}

$\begin{array}{lllll} & \mathbf{I N a}_{\mathbf{N a}}>\mathbf{1} \mathbf{n A} & \mathbf{I}_{\mathrm{Na}+}<\mathbf{1} \mathbf{n A} & \mathbf{I}_{\mathbf{C a}^{2+}} & \text { MSN-like } \\ \mathbf{W T}(\mathrm{n}=18) & 15(83 \%) & 3(17 \%) & 10(56 \%) & 5(33 \%) \\ \mathbf{z Q 1 7 5}(\mathrm{n}=31) & 25(81 \%) & 6(19 \%) & 14(45 \%) & 6(24 \%)\end{array}$

\section{B: Cell Membrane Properties of hNSCs Displaying $\mathrm{ICa}^{2+}$ Implanted in WT or zQ175 Mice} Capacitance $(\mathbf{p F})$ Input Resistance (MS) Time Constant (ms) WT $(n=10)$ $103.2 \pm 12$ $780.0 \pm 104$ $2.1 \pm 0.3$ $\mathbf{z Q 1 7 5}(\mathrm{n}=14)$

$109.2 \pm 14$

$778.2 \pm 137$

$1.8 \pm 0.2$

\section{C: Cell Membrane Properties of Recorded hNSCs Displaying Large, MSN-like $\mathrm{ICa}^{2+}$ Implanted in WT or zQ175 Mice}

\section{Capacitance (pF) Input Resistance (MS) Time Constant (ms)}
WT $(n=5)$
$89.2 \pm 9$
$945.2 \pm 145$
$1.6 \pm 0.3$

zQ175 (n=6)

$107.6 \pm 12$

$727.8 \pm 156$

$1.6 \pm 0.3$ 

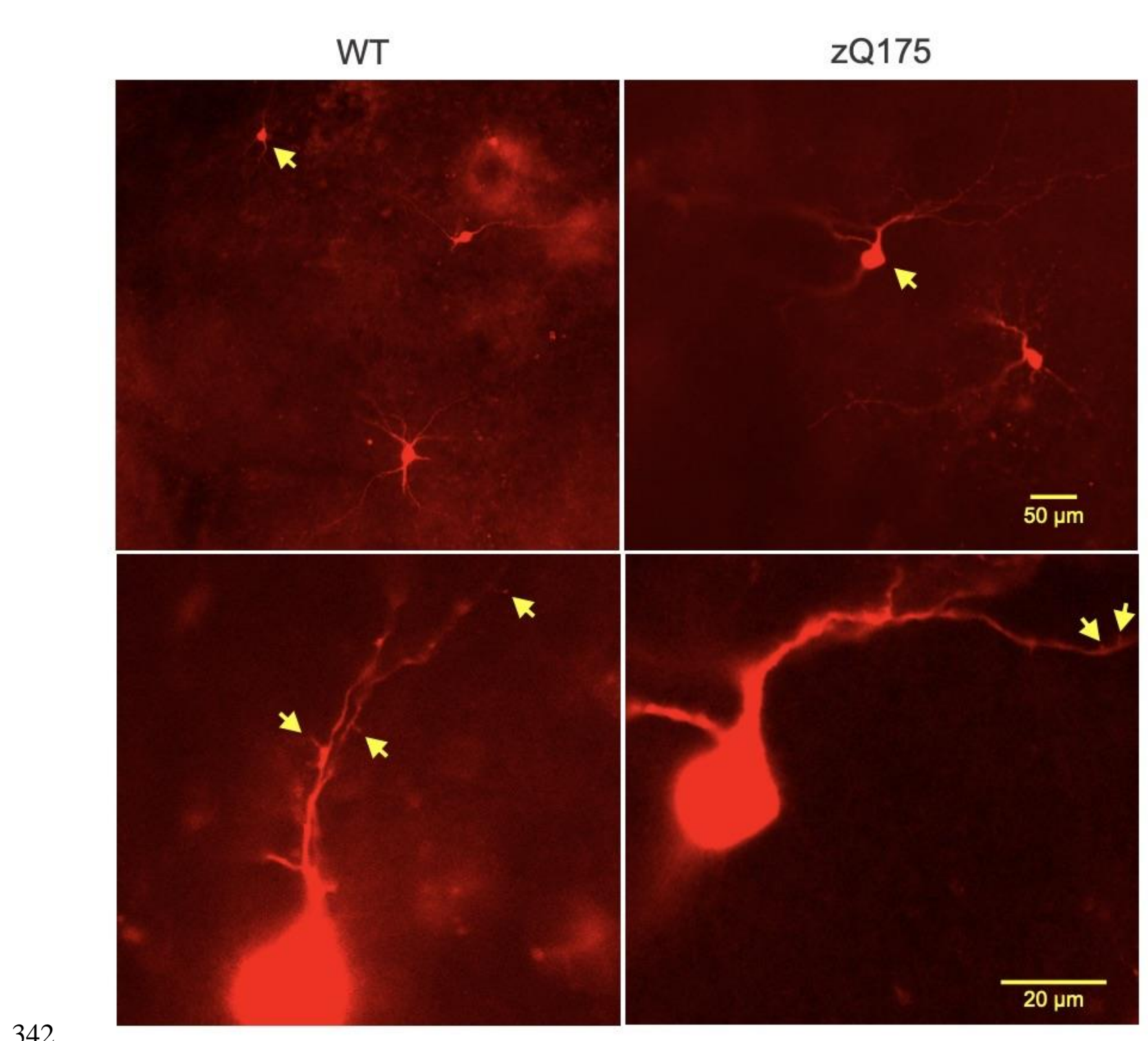

Figure 5: Biocytin-filled hNSCs recorded in WT and zQ175 mice in host striatum. Upper panels show low-magnification images of several hNSCs. Arrows indicate two cells that displayed MSN-like electrophysiological properties. Lower panels show processes from the same cells at higher magnification. Arrows indicate possible dendritic spines. 
$\mathrm{Na}^{+}$and outward $\mathrm{K}^{+}$currents, and could fire repetitive action potentials. We were able to recover $\sim 50 \%$ of biocytin-filled hNSCs (9/18 or $50 \%$ and $15 / 31$ or $48 \%$ recorded in WT and zQ175 mice, respectively). Importantly, over $80 \%$ of those recovered clearly co-immunostained with the SC121 and Ku80 markers (8/9 or $89 \%$ and $12 / 15$ or $80 \%$ in WT and zQ175 mice, respectively), thus confirming their human origin. Post-recording immunostaining of biocytin-filled large hNSCs with SC121 and Ku80 (with strepavidin-Alexa 594 for cell visualization) in fixed slices revealed hNSCs with relatively large somata (compared to host MSNs) and extensively branched processes.

356 Other visible hNSCs were smaller in size and had either many or a small number of processes. The

357 large hNSCs had cell diameters of up to $\sim 25 \mu \mathrm{m}$ and were positive for both SC121 and Ku80

358 immunostaining (Fig. 6). Another important difference was that, compared with host MSNs or 359 MSN-like hNSCs, many large hNSCs fired spontaneously. In cell-attached recording mode, cells 360 fired rhythmically and also received rhythmic GABAergic synaptic inputs. We tentatively 361 concluded these inputs were GABAergic because the GABA reversal potential was around -60

$362 \mathrm{mV}$ (Suppl. Fig. 2). Due to this rhythmic input, one possibility is that the source of this GABA 363 input is from other mature hNSCs, as hNSCs remained in close proximity. In addition, host 364 GABAergic interneurons, such as the somatostatin-expressing or neuropeptide Y (NPY)365 expressing interneurons that fire spontaneously, may contribute to these rhythmic inhibitory events recorded in hNSCs. Another type of recorded hNSC $(n=3)$ resembled low-threshold spiking (LTS)

367 striatal interneurons (Suppl. Fig. 3A). In current clamp mode these cells displayed prominent 368 delayed rectification at hyperpolarized membrane potentials (Suppl. Fig. 3B). When depolarized 369 they discharged in bursts of action potentials, seemingly riding on a low-threshold $\mathrm{Ca}^{2+}$ spike 370 followed by a membrane hyperpolarization, which produced spontaneous oscillations and bursts 
371 of action potentials (Suppl. Fig. 3C). The last type of hNSC (n=2) resembled cholinergic (ChAT-

372 expressing) interneurons, also known as striatal tonically active neurons (TAN). They displayed

373 rhythmic firing $(2-3 \mathrm{~Hz})$ and prominent delayed inward rectification. Electrophysiological

374 identification of these interneurons was supported by IHC detection of appropriate markers

375 (Suppl. Fig. 4 and 5).

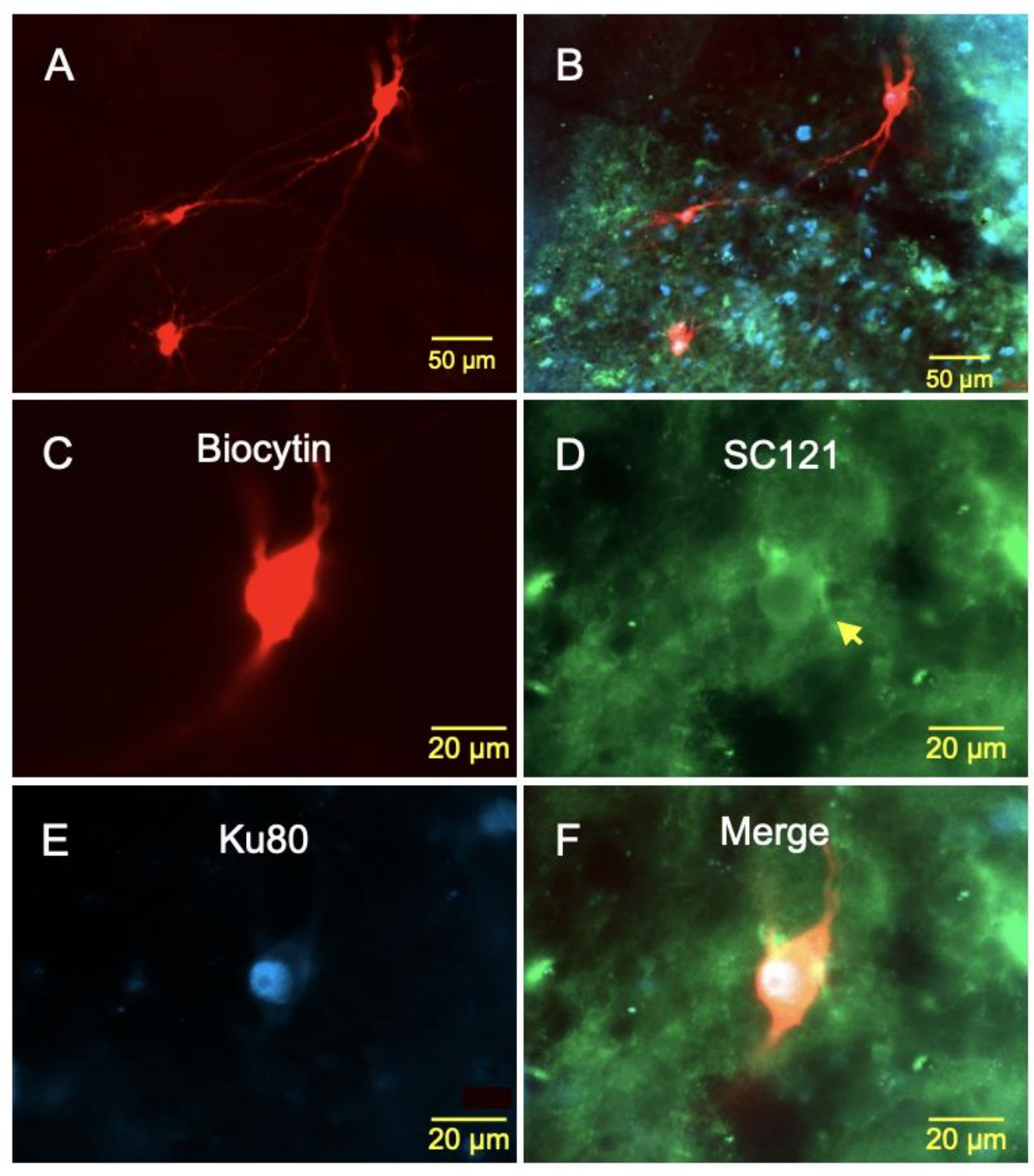

377 Figure 6: Images of large hNSCs from a zQ175 mouse, which displayed interneuron-like 378 electrophysiological properties. A. Four medium to large hNSCs were recorded within the graft. 379 B. The same image showing staining for the human markers SC121 (cytoplasmic, green) and Ku80 380 (nuclear, blue). C. Fluorescent image of one of the large biocytin-filled hNSCs. Immunostaining 
381 of the same hNSC with human stem cell markers SC121 (arrow in D) and Ku80 (E). F. Merged 382 image showing biocytin and the two human stem cell markers. The electrophysiology of this 383 interneuron-like hNSC is shown in Fig. 4 (right panels). were examined by holding the membrane at $-70 \mathrm{mV}$. GABAergic inputs were examined by holding

387 the membrane at $+10 \mathrm{mV}$. Immature hNSCs displayed very few synaptic inputs whereas mature 388 hNSCs had a wide range of synaptic inputs, some with frequencies as high as those recorded from MSNs [2.1 $\pm 0.2 \mathrm{~Hz}$ (range 0.2-6.9 Hz) for MSNs versus $1.5 \pm 0.2 \mathrm{~Hz}$ (range 0.0-8.7 Hz) for hNSCs]. Based on the frequency of spontaneous synaptic activity, cells displaying $\mathrm{Na}^{+}$currents could be

391 divided into those with high IPSC and high EPSC frequencies, high IPSC and low EPSC 392 frequencies, and low IPSC and high EPSC frequencies. As expected, large hNSCs displayed higher 393 frequencies than those of immature-looking hNSCs (Fig. 7A-C). Some hNSCs (n=2) also were 394 tested for their ability to respond to electrical stimulation in the vicinity of the graft. Both cells 395 responded to the electrical stimulation displaying both glutamatergic and GABAergic responses, 396 as demonstrated by specific blockade with appropriate receptor antagonists (Fig. 7D). Thus, these 397 studies provided evidence that hNSCs establish synaptic contacts with the host and probably among hNSCs as well. 


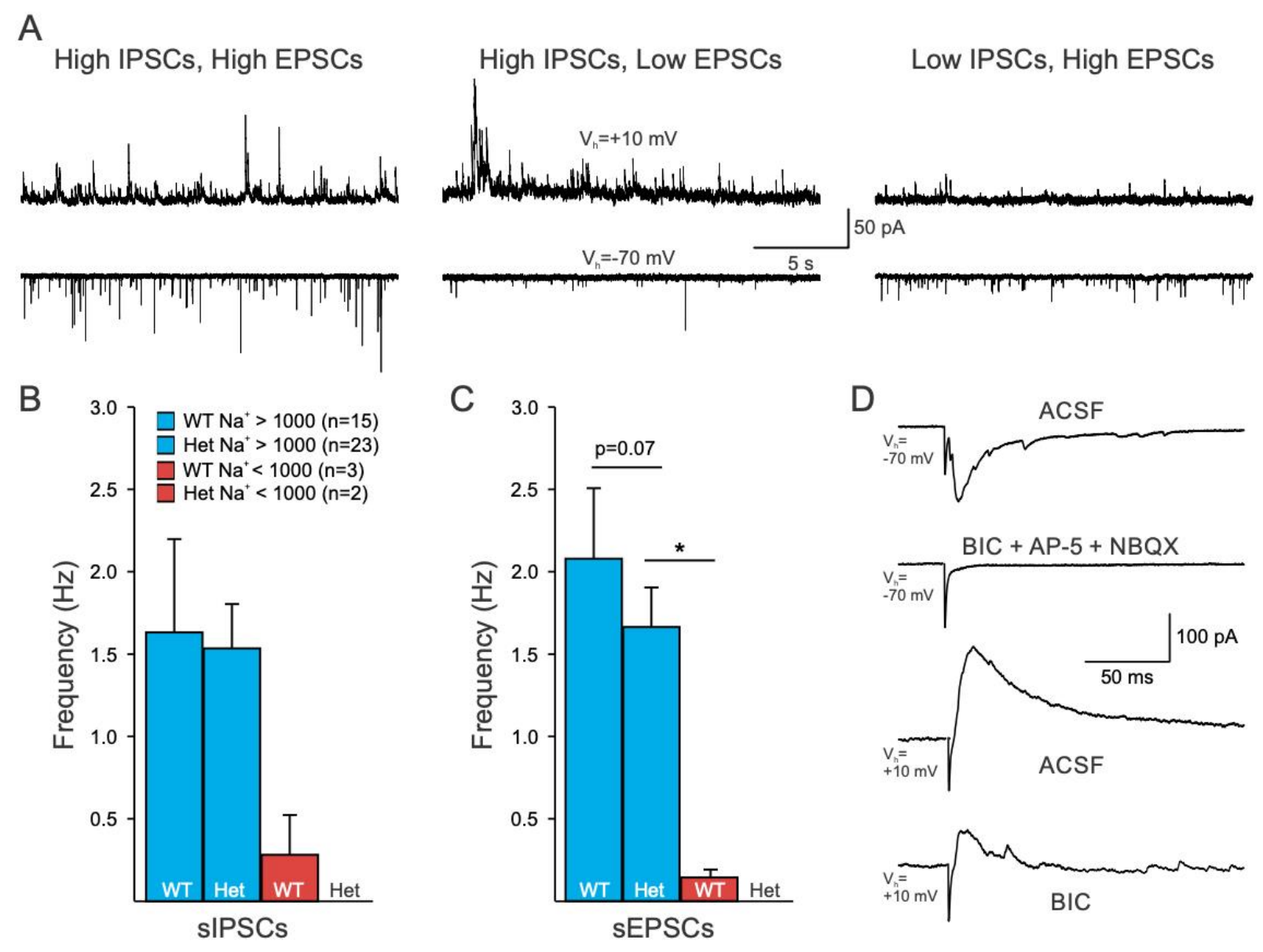

Figure 7: hNSCs in WT and Q175 mice display multiple synaptic inputs. A. Sample traces of sIPSCs and sEPSCs recorded from hNSCs in a zQ175 mouse in ACSF. B and C. Summary of the sIPSC and sEPSC frequencies from hNSCs categorized by the size of their $\mathrm{Na}^{+}$currents. Statistical significance was measured between groups using Kruskal-Wallis one-way ANOVA on ranks followed by Holm-Sidak pairwise comparisons, where $* \mathrm{p}=0.024$ for $\mathrm{Het} \mathrm{Na}^{+}>1000 \mathrm{pA}$ versus WT $\mathrm{Na}^{+}<1000$ pA. D. Responses evoked by electrical stimulation (0.1-0.5 mA, $1 \mathrm{~ms}$ duration) of host striatal neurons (about $200 \mu \mathrm{m}$ lateral to the graft) in a hNSC from a zQ175 mouse. Glutamatergic $\left(\mathrm{V}_{\mathrm{h}}=-70 \mathrm{mV}\right)$ and GABAergic $\left(\mathrm{V}_{\mathrm{h}}=+10 \mathrm{mV}\right)$ responses were reliably evoked by electrical stimulation. Responses were blocked by glutamate and $\mathrm{GABA}_{\mathrm{A}}$ receptor antagonists respectively.

\section{Ultrastructural Evidence that hNSCs Establish Synaptic Contacts Within and Outside the}

412 Graft: To examine the morphology of implanted hNSCs and determine whether synaptic contacts

413 are present between the host and transplanted hNSCs, thus further supporting the 414 electrophysiology results, we performed electron microscopy (EM). EM studies provided 
415 additional anatomical evidence that hNSCs in the graft received innervation from host neurons. A

416 subset of the mice implanted at UCI (3 females per group, zQ175 hNSC implanted) were sent live

417 to the Portland VA Medical Center where the mice were perfused with fixative, the brains were

418 collected and fixed for EM tissue processing. Results indicate that mouse host cell nerve termini

419 make both symmetrical and asymmetrical synaptic contacts with implanted ESI-017 hNSCs. As a

420 proof-of-principle, in a subset of samples we performed double-immunostaining for vGlut1 (which

421 labels cortical glutamate terminals) and SC121. There were mouse host cell nerve termini that

422 were positively labeled with vGlut1 making asymmetrical synaptic contacts with ESI-017 hNSCs

423 (Fig. 8A), suggesting that mouse (host) cortical neurons contribute to these connections. However,

424 it is also possible that the other major host nerve terminal input to the ESI-017 hNSC implanted

425 neurons, where an asymmetrical synaptic contact is observed (Fig. 8B, C), may be from the 426 thalamus.

427 Within the implant, of the host (non-labeled) terminals contacting SC121+ dendrites/spines

428 in the implant site, $60 \%$ of the asymmetrical contacts were on dendrites and $40 \%$ on spines (total

429 of 35 observations), suggesting contacts with MSN-like hNSCs. Of the host contacting SC121+

430 labeled dendrites, if the synaptic contact was symmetrical, $100 \%$ of those contacts were on the

431 dendrite (22 observations). Of all the host (non-labeled) contacts onto SC121+ labeled cells in the

432 implant area, $62.1 \%$ were asymmetrical while $37.9 \%$ of the contacts were symmetrical (total of 58

433 observations).

434 Within the implant, the percentage of SC121+ nerve terminals contacting SC121+ 435 dendrites was determined. We found that of those total synaptic contacts, $71.3 \%$ were making an 436 asymmetrical synaptic contact, with $27.8 \%$ making a symmetrical contact (total of 115 437 observations). About $1 \%$ of the contacts could not be determined as to whether they were 

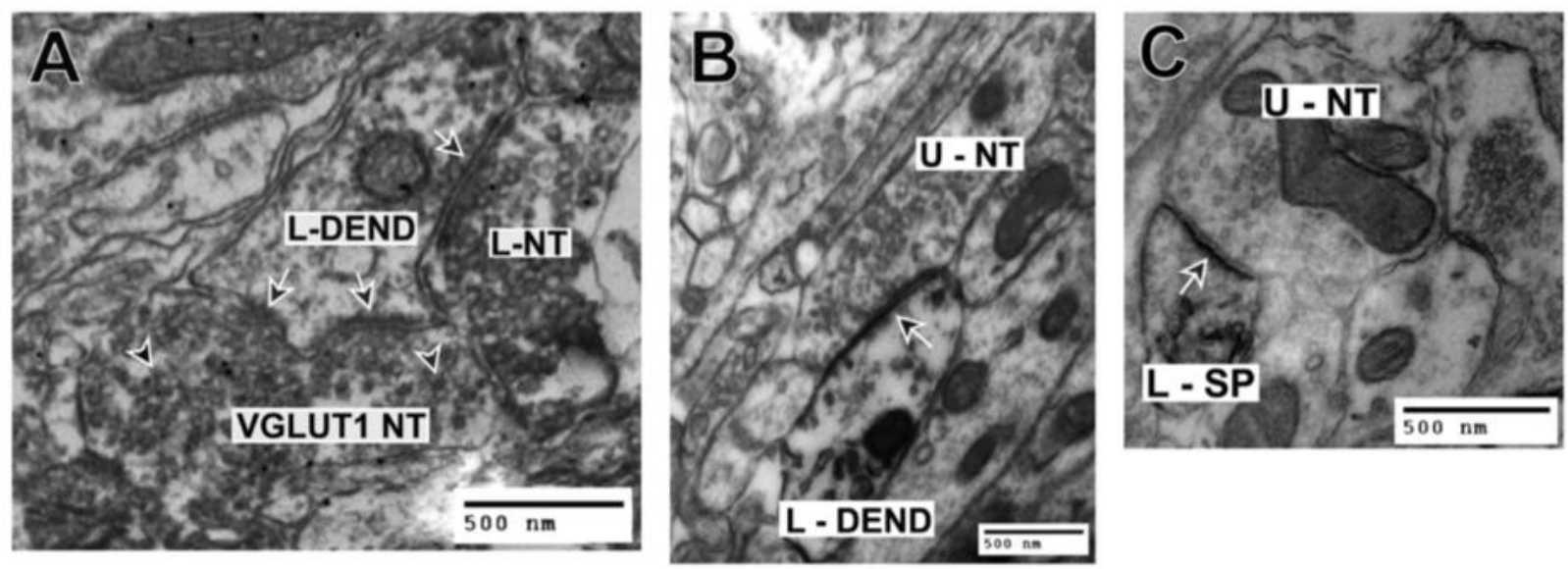

Asymmetrical

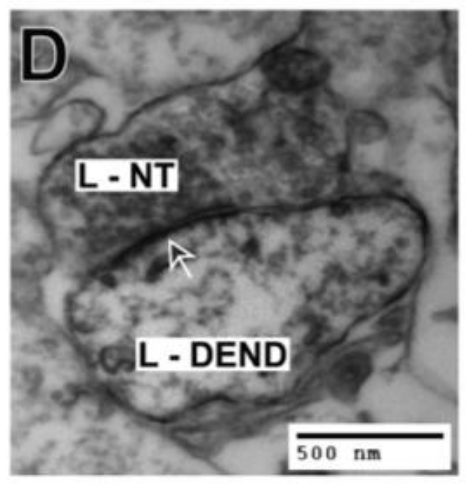

Asymmetrical

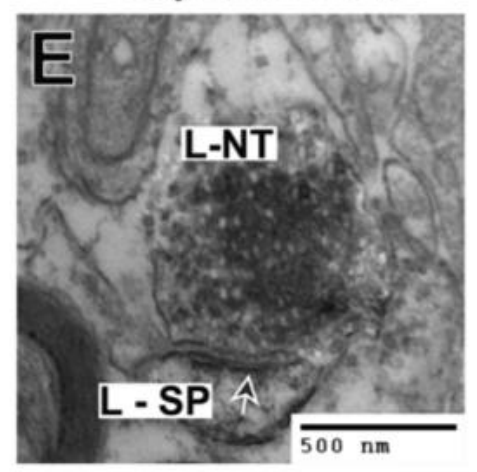

Symmetrical

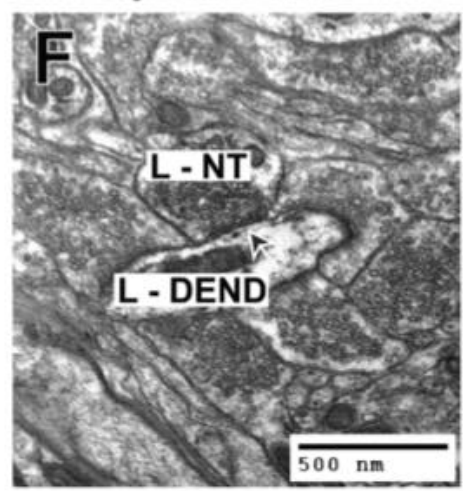

442 Figure 8: EM studies revealed that the host tissue makes synaptic contacts with ESI-017 443 hNSCs in zQ175 mice within the implantation site: A. hNSC/DAB labeled nerve terminal (L444 NT) making a symmetrical synaptic contact (single black arrow with white outline) with an 445 hNSC/DAB labeled dendrite (L-DEND). Vglut1 labeled nerve terminal (VGlut1 NT) making an asymmetrical synaptic contact with the head of a stubby spine that contains a perforated postsynaptic density (two black arrows with white outline pointing to synaptic contact). The VGlut1 NT (black arrowheads with white outlining-VIP labeling), is distinguished from the adjacent nerve terminal (which is DAB labeled). The primary origin of VGLUT-1 containing neurons is the cortex. B. An unlabeled nerve terminal (U-NT) making an asymmetrical synaptic contact (arrow) with an underlying hNSC positive labeled dendrite (L-DEND) (note the darkened $\mathrm{DAB}$ reaction product within the dendrite). The unlabeled nerve terminal might originate from either the host striatum, thalamus or cortex (see panel A), while the labeled dendrite originates from the implanted stem cells. C. An unlabeled nerve terminal (U-NT) is making an asymmetrical synaptic contact (arrow) with an underlying hNSC positive/labeled dendritic spine (L-SP) (note the darkened $\mathrm{DAB}$ reaction product within the spine). As in panel $\mathrm{B}$, the unlabeled nerve terminal 
might originate from either the host striatum, thalamus or cortex (see panel A), while the labeled dendritic spine originates from the implanted stem cells. D. A labeled nerve terminal (L-NT) is making an asymmetrical synaptic contact (arrow) with an underlying hNSC positive/labeled dendrite (L-DEN) (note the darkened DAB reaction product within the nerve terminal and dendrite). The labeled nerve terminal and dendrite originate from the implanted stem cells. E. A labeled nerve terminal (L-NT) is making an asymmetrical synaptic contact (arrow) with an underlying hNSC positive/labeled dendritic spine (L-SP) (note the darkened DAB reaction product within the nerve terminal and spine). The labeled nerve terminal and spine originate from the implanted stem cells. F. A labeled nerve terminal (L-NT) is making a symmetrical synaptic contact (arrow) with an underlying hNSC positive/labeled dendrite (L-DEN) (note the darkened DAB reaction product within the nerve terminal and dendrite). The labeled nerve terminal and dendrite originate from the implanted stem cells. contact while $9.4 \%$ were making a symmetrical contact (total of 32 observations). Of the $90.6 \%$

474 making an asymmetrical synaptic contact, $79.3 \%$ were contacting spines while $20.7 \%$ were

475 contacting dendrites. There were also nerve terminals from the host striatum (i.e., SC121 negative) contacting SC121+ dendrites. Of those contacts, $52.6 \%$ were asymmetrical and $47.4 \%$ were making a symmetrical contact (total of 19 observations) (Suppl. Fig. 6A-D).

480 zQ175 Mice: Given that we have previously shown that excitatory and inhibitory inputs to striatal

481 MSNs and cortical pyramidal neurons in the zQ175 mouse model are altered (Indersmitten et al.,

482 2015), we obtained whole-cell voltage clamp recordings to measure membrane and synaptic 483 properties of neighboring host MSNs to determine whether transplanted hNSCs conferred modulatory outcomes (Fig. 9A-D). Data from WT mice implanted with hNSCs and injected with

485 vehicle only were pooled as there were no consistent differences in measures from MSNs between 
the two groups (Table ID). We observed an improvement in the cell membrane properties of zQ175 MSNs from hNSC-implanted mice compared to zQ175 MSNs from mice receiving the vehicle only (Fig. 9A). Previously, we showed MSNs from symptomatic zQ175 mice have higher membrane input resistances than MSNs from WT mice (Indersmitten et al., 2015). Compared with WT MSNs (hNSC-implanted and vehicle-injected, combined), zQ175 MSNs from vehicle-

491 injected mice had significantly higher input resistances (WT 91.6 \pm 10.1 versus Q175-Veh 170.2 $\pm 19.7 \mathrm{M} \Omega, \mathrm{p}<0.001$; Kruskal-Wallis ANOVA of ranks, followed by Holm-Sidak pairwise comparisons). Although input resistances were slightly higher in zQ175-hNSC MSNs (120.1 \pm 13.1

$494 \mathrm{M} \Omega$ ) compared to WT MSNs, this difference was not statistically significant demonstrating 495 improvement in this electrophysiological property. Input resistances were significantly lower in 496 MSNs from hNSC-implanted zQ175 mice compared to MSNs from vehicle-injected mice $497(\mathrm{p}=0.04)$. There were no significant differences in cell membrane capacitances or membrane time 498 constants across all three groups (Fig 9A). (Indersmitten et al., 2015) the frequency of sIPSCs recorded at a holding potential of $+10 \mathrm{mV}$ was increased compared to WT MSNs (Fig. 9C). The increase was statistically significant in MSNs from Q175 mice injected with vehicle (WT 1.3 \pm 0.2 versus Q175-Veh 2.2 $\pm 0.3 \mathrm{~Hz}, \mathrm{p}=0.047$;

503 Kruskal-Wallis ANOVA of ranks, followed by Holm-Sidak pairwise comparisons) and although 504 the sIPSC frequency was slightly higher in MSNs from hNSC-implanted zQ175 mice $(2.0 \pm 0.3$ $505 \mathrm{~Hz}$ ) compared to WT MSNs, it was not statistically significant (p=0.114) (Fig. 9C) demonstrating 506 that the transplant reduced the increase in sIPSCs in MSNs from the zQ175 mice compared to WT 507 mice. From the same cells, we recorded sEPSCs at a holding potential of $-70 \mathrm{mV}$ and in the 508 presence of a $\mathrm{GABA}_{\mathrm{A}}$ receptor antagonist $(\mathrm{BIC}, 10 \mu \mathrm{M})$. We observed a trend for decreased sEPSC 
509 frequency in MSNs from zQ175-Veh mice $(1.8 \pm 0.3 \mathrm{~Hz})$ compared to WT MSNs $(2.8 \pm 0.5 \mathrm{~Hz})$.

510 Similarly, there was a trend for an increase in the frequency of sEPSCs in MSNs from the hNSC

511 transplanted zQ175 mice $(2.4 \pm 0.5 \mathrm{~Hz})$.

A
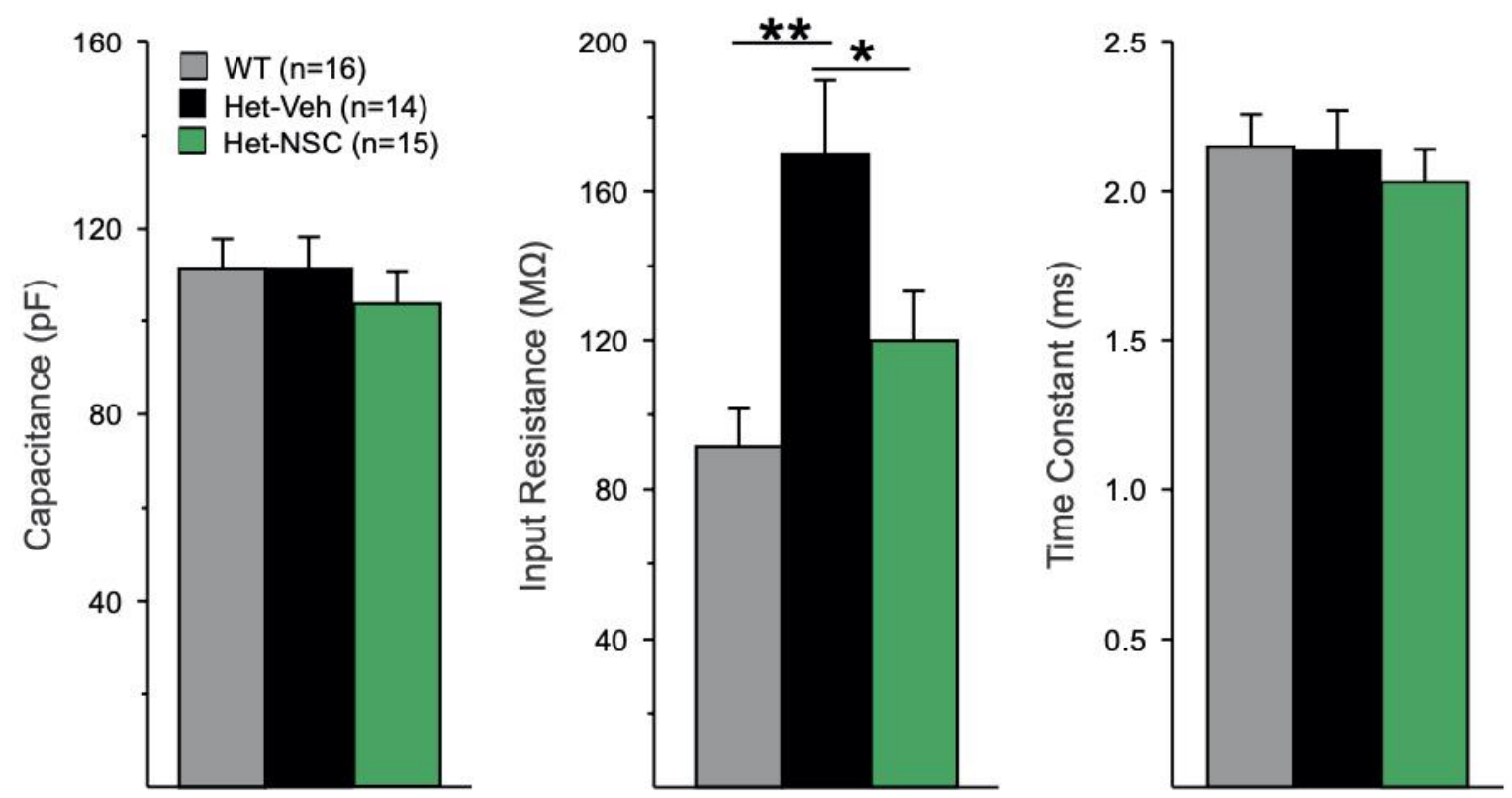

B

C

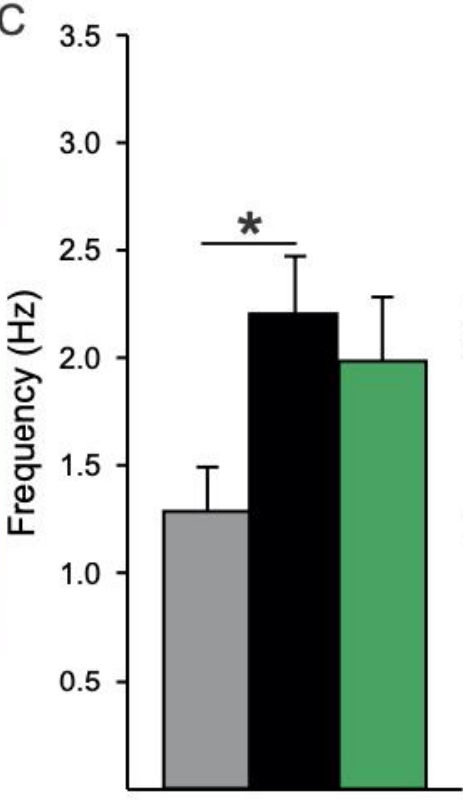

sIPSCs

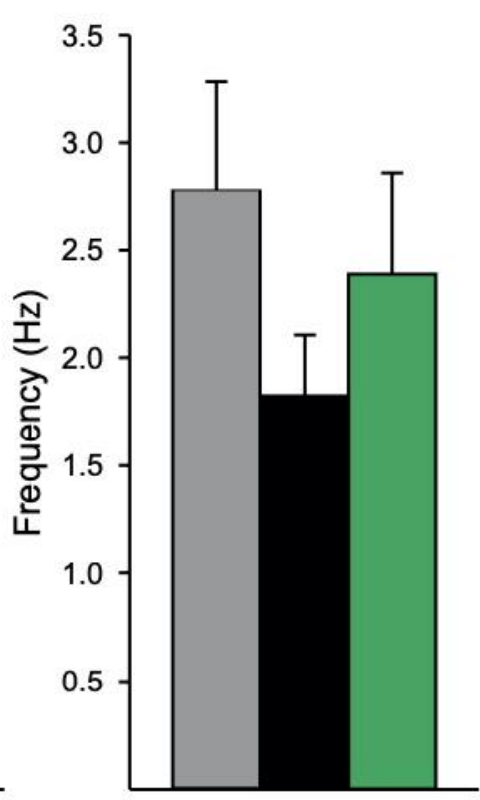

sEPSCs
Host MSN

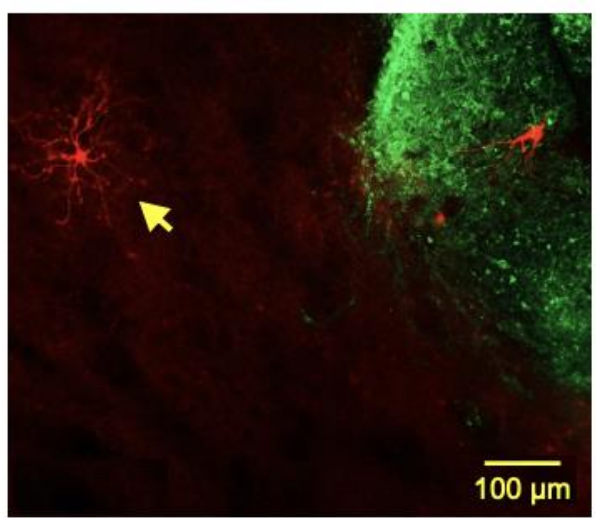

513

514
Figure 9: Rescue of some electrophysiological alterations. A. Cell membrane properties were recorded at a holding potential of $-70 \mathrm{mV}$. B. Fluorescent image of a recorded and biocytin-filled 
MSN [yellow arrow pointing to filled neuron (red)] near SC121 immunostained cells and processes (green). C. Effects on inhibitory and excitatory synaptic activity. Statistical significance was measured between groups using Kruskal-Wallis one-way ANOVA on ranks followed by HolmSidak pairwise comparisons, In A. p $<0.001$ for WT versus Het-Veh (**) and p=0.04 for Het-Veh versus Het-NSC (*). In C. p=0.047 for WT versus Het-Veh (*).

Taken together, these data show long-term survival and differentiation of hNSCs into mainly neuronal lineages including a subset of mature-like MSNs and interneurons. The engrafted

523 human cells establish connections with the host neurons and rescue specific electrophysiological 524 and behavioral pathologies.

\section{Discussion}

527 A major challenge in regenerative medicine approaches to treat neurodegenerative diseases, 528 including HD, is enabling long-term assessment of cell fate, functional properties and potential 529 rescue of disease-associated phenotypes (Jia et al., 2020; Kim et al., 2020). Here we evaluated 530 whether hNSCs implanted in the striata of zQ175 mice are viable and integrate into the host tissue 531 at a time point of 8 months after grafting (equating to roughly a third of the captive's mouse 2-

532 year lifespan). hNSCs survived and while most hNSCs had properties of immature neurons, 533 approximately $20 \%$ of the cells evolved into more mature neurons with MSN- or interneuron-like 534 properties and marker expression. Transplanted hNSCs receive synaptic inputs from neighboring 535 cells or from the host, and innervate other hNSCs or host cells. Notably, grafted hNSCs increased 536 striatal BDNF and pERK levels, reduced mHTT aggregated species, and ameliorated selected 537 behavioral deficits of symptomatic zQ175 mice. Further, grafted cells modified host MSNs and 538 rescued some of the altered membrane and synaptic properties observed in symptomatic mice. 539 Thus, the mechanisms whereby implanted neurons rescue HD alterations appear to involve 
540 improved striatal MSN membrane properties and circuit connectivity, BDNF production, and

541 prevention of the accumulation of mHTT aggregating species

542 To the best of our knowledge, this is the first study to examine, long-term (up to 8 months),

543 electrophysiological and morphological properties of grafted hNSCs in a genetic mouse model of

544 adult-onset HD. Also, it is the first to demonstrate that mature hNSCs evolve into the main types

545 of resident neuronal populations in the striatum including not just MSNs, but also GABAergic and

546 cholinergic interneurons. This is important as a comprehensive reconstruction of the striatal

547 circuitry requires not just the presence of MSNs but a wide variety of interneurons which also are

548 significantly affected in HD (Cepeda et al., 2013; Reiner et al., 2013; Holley et al., 2015; Holley

549 et al., 2019a; Holley et al., 2019b).

550 Previously we demonstrated that hNSCs are viable and integrate into the host striatum in a

551 severe model of HD, the R6/2 (Holley et al., 2018; Reidling et al., 2018). However, due to rapid

552 progression of the phenotype in these mice, examination of transplanted hNSCs was limited by

553 time, about 4-6 weeks after implantation. We also reported data from the long-lived homozygous

554 Q140 HD mouse model (Reidling et al., 2018), however, cell survival was not optimal. This most

555 likely occurred due to insufficient immunosuppression methods, and measurements of cell

556 differentiation or electrophysiology and connectivity visualized by EM were not feasible. Here we

557 show that hNSCs can survive 8 months after injection, integrate into the host striatum, and improve

558 some of the abnormal MSN membrane and synaptic properties of the heterozygous zQ175 HD

559 model. Further, a subset of hNSCs become more mature and display properties similar to those of

560 MSNs and some types of interneurons. EM and electrophysiology also suggest connections from

561 the host may originate in the cortex and support a potential reconnection of the corticostriatal

562 pathway that is lost during HD progression and that reconnection could contribute to restoration 
563 of normal motor and cognitive functions. We hypothesize that the higher frequencies of synaptic

564 inputs are due to the maturation and integration of hNSCs within the host tissue, as we did not

565 observe hNSCs with these synaptic properties in our previous study using R6/2 hNSC-implanted

566 mice. Unlike the R6/2 mice, MSNs from zQ175 mice do not exhibit epileptiform activity in the

567 presence of BIC. The R6/2 mouse model demonstrates cortical hyperexcitability that can be

568 exacerbated pharmacologically when inhibition is reduced (Cummings et al., 2009). This is

569 reflected in R6/2 MSNs as large amplitude excitatory events followed by a barrage of high

570 frequency, small amplitude events. We did not observe this electrophysiological phenotype in any

571 of the zQ175 or WT MSNs.

572 Electrophysiologically, $\sim 80 \%$ of hNSCs remained "immature", despite surviving in the

573 graft for 8 months. It is unknown why these cells do not differentiate. It is possible that with longer

574 implantation time these cells also become more mature. We previously showed that transplanted

575 hNSCs in R6/2 mice exhibited evidence of neuron-restricted progenitor markers DCX, Beta-III

576 tubulin, and MAP-2 (Reidling et al., 2018). As hNSCs typically take several months to terminally

577 differentiate during development, we expected to observe further differentiation of transplanted

578 cells in the zQ175 8-month implant cohort. Interestingly, although we found this to be the case

579 with some cell staining for the post-mitotic neuronal marker NeuN, as well as interneuron and

580 MSN markers, we still observed clusters of ESI-017 hNSCs to be DCX positive after 8 months.

581 Perhaps the DCX positive hNSCs have not received the signals to differentiate as many seem to

582 be on the interior of the implant. It is important to note that the hNSCs appear to have received

583 signals to stop proliferating (no Ki67 or EdU incorporation) and start down a path to differentiate

584 (loss of nestin). Even though most cells did not fully differentiate and did not become more mature, 
585 they still looked healthy and displayed neuronal properties, including the capacity to generate

586 action potentials.

Although we can conclude that about $20 \%$ of the large hNSCs display physiological

588 features of mature neurons, it is difficult to determine the specific cell-types based solely on their

589 electrophysiological properties. Supporting evidence was provided by IHC and the presence of

590 specific striatal neuronal markers. MSN-like hNSCs displayed $\mathrm{Ca}^{2+}$ currents typically observed in

591 mature MSNs and IHC demonstrated the presence of DARPP-32 and Ctip2, which label striatal

592 MSNs. Other hNSCs fired rhythmically, had increased input resistances (compared to MSNs),

593 lacked characteristic $\mathrm{Ca}^{2+}$ currents, and received rhythmic GABAergic synaptic events, suggesting

594 that these cells could be GABAergic interneurons. In support, IHC from these grafts indicated the

595 presence of GAD and CR, specific interneuron markers. Some large hNSCs also displayed

596 rhythmic bursting and low-threshold spikes, reminiscent of the somatostatin-expressing (LTS)

597 interneurons (Tepper et al., 2018; Holley et al., 2019b). This observation is significant in terms of

598 HD because these two interneuron subtypes are spared during disease progression. In fact, CR+

599 interneurons appear increased in HD (Cicchetti and Parent, 1996), suggesting that they could have

600 neuroprotective properties or alternatively they are selected for within the HD niche. Indeed, both

601 somatostatin and calretinin have been shown to be neuroprotective (Kumar, 2008) and a study on

602 grafted fetal striatal tissue demonstrated the presence of graft-derived neurons expressing DARPP-

603 32, calretinin and somatostatin (Capetian et al., 2009). Another possibility is that some large

604 hNSCs could have evolved into NPY interneurons. Interestingly, in HD, MSNs expressing NPY

605 are spared and their numbers are even upregulated in HD patients (Wagner et al., 2016). Based on

606 passive and active membrane properties, some cells also differentiated into large cholinergic 
607 interneurons. In contrast, it seems unlikely that differentiated hNSCs became fast-spiking

608 interneurons, at least in a mature state.

609 Results of cell fate in our HD mouse studies uniquely appear to follow a neuronal

610 developmental path in contrast to a more gliogenic outcome, potentially due to the differentiation

611 potential of the starting material or the transplantation niche (Goldberg et al., 2017; Qian et al.,

612 2020; Yoon et al., 2020). A recent study using a rat model of HD induced by intrastriatal quinolinic

613 acid injection, showed that human embryonic stem cell-derived MSN progenitors differentiate in

614 vitro, undergo maturation, integrate into host circuits, and display properties similar to those of the

615 host striatum 2 months after transplantation (Besusso et al., 2020), suggesting feasibility of

616 transplanting differentiated MSN progenitors. Notably, behavioral studies in this model

617 demonstrated functional recovery of some impaired sensorimotor responses but not in more

618 complex behaviors (e.g., rotarod test). Some cells were proliferative, the yield of DARPP32/Ctip2

619 double-labeled MSNs was relatively low, and there was some degree of contamination from

620 cortical neurons. However, it is not known whether excitotoxicity models reflect the biochemical

621 environment of the genetic mutation. Interestingly in that study, similar to ours, a low percentage

622 of grafted cells expressed interneuronal markers (calbindin and calretinin), however these cells

623 were not characterized electrophysiologically. Other strategies to generate striatal neurons are

624 under investigation. For example, a recent study used an in vivo cell conversion technology to

625 reprogram striatal astrocytes into GABAergic neurons through AAV-mediated ectopic expression

626 of NeuroD1 and Dlx2 transcription factors (Wu et al., 2020). The striatal astrocyte-converted

627 neurons showed action potentials and synaptic events, and projected their axons to the appropriate

628 target regions. Behavioral analyses of these treated R6/2 mice showed a significant extension of

629 life span and improvement of motor deficits (Wu et al., 2020). 
In conclusion, our studies support future development of stem cell-based therapies. While mHTT/HTT-lowering strategies and gene editing are promising as therapies and are in various

632 stages of clinical trials, a pressing issue is how to replace the striatal cell loss occurring in HD 633 patients even prior to overt symptomatic onset. The present results support our previous findings

634 that implanted cells may provide nursing effects through enhanced BDNF levels and reduction of 635 pathological mHTT. Importantly, hNSCs establish synaptic contacts with host cells and among 636 themselves, differentiate into a wide variety of striatal resident cells, and form the building blocks 637 for circuit regeneration. Given the electrophysiological and EM results presented here, there is also 638 promise that over time, transplanted cells can make beneficial synaptic connections and replace 639 lost functions. Thus, our preclinical study demonstrates that hNSCs transplanted into a relevant 640 HD model brain survive for long periods of time and may potentially be utilized for restoration of 641 circuity and cell replacement in the clinic.

\section{Methods}

644 Mice: All experimental procedures were in accordance with the Guide for the Care and Use of 645 Laboratory Animals of the NIH and animal protocols were approved by Institutional Animal Care 646 and Use Committees at the University of California Irvine (UCI), the University of California Los

647 Angeles (UCLA), and the Portland VA Medical Center, AAALAC accredited institutions. zQ175 648 heterozygous (Het) mice and their wildtype (WT) littermates were obtained from breeding 649 colonies maintained at UCI (zQ175 Het mice had 163-199 CAG repeats, Laragen, Culver City, 650 CA). All mice were housed on a 12/12-hr light/dark schedule with ad libitum access to food and 651 water. Mice were group-housed as mixed treatment groups and only males were single-housed for 652 the running wheel test. Groups included: 10 male zQ175 Het hNSC, 8 female Het hNSC, 9 male 
653 zQ175 Het vehicle, 9 female zQ175 Het vehicle, 7 male WT hNSC, 7 female WT hNSC, 6 male

654 WT vehicle, 6 female WT vehicle.

656 Cells: The use of hESCs and hNSCs was approved by Human Stem Cell Research Oversight

657 Committees (hSCRO) at UCI, UCLA, and UC Davis. ESI-017 is one of the six clinical-grade

658 hESC lines generated from supernumerary embryos by the Singapore Stem Cell Consortium

659 (Crook et al., 2007). Their use for therapeutic application adheres to US FDA regulations for use

660 of human cells. Of those lines, four (including ESI-017) were chosen for the generation of Good

661 Medical Practice (GMP) hESC banks for preclinical research based on the absence of human and

662 non-human pathogens (Crook et al., 2007; Sivarajah et al., 2010). Subsequently, an hNSC line was

663 differentiated from the GMP-grade hESC line ESI-017 as described previously (Reidling et al.,

664 2018). ESI-017 hNSCs were acquired as frozen aliquots, thawed, and then cultured for a minimal

665 time out of thaw (2-3 days) using the same media reagents as the GMP facility prior to dose

666 administration. The cells were not passaged.

668 Surgery: Two and a half month-old zQ175 Het mice and WT littermates were anesthetized, placed

669 in a stereotaxic frame and injected with either $100,000 \mathrm{hNSCs}$ per side $(2 \mu \mathrm{l} /$ injection $)$ or vehicle

670 (2 $\mu \mathrm{l} \mathrm{HBSS}$ with $20 \mathrm{ng} / \mathrm{ml}$ epidermal growth factor [STEMCELL Technologies, \#78003] and

671 human fibroblast growth factor [STEMCELL, \#78006]) as a control treatment using a $5 \mu 1$

672 Hamilton microsyringe (33-gauge) and an injection rate of $0.5 \mu \mathrm{l} / \mathrm{min}$. Coordinates relative to

673 Bregma were AP: 0.00, ML: +/- 2.00, and DV -3.25 mm. For immunosuppression, all mice

674 received IP injections of cyclosporine $(10 \mathrm{mg} / \mathrm{kg}$, daily thereafter) and mouse CD4 Ab (10 mg/kg, 
675 weekly thereafter) the day before surgery and continued until mice were sacrificed (8 months after

676 implantation).

678 Biochemical, Molecular, and Immunohistochemical Analyses: Four male mice per group were 679 given IP injections of EdU (Thermofisher Scientific) $24 \mathrm{hr}$ prior to sacrifice. Mice were euthanized 680 by pentobarbital overdose and perfused with 0.01 M PBS. Striatum and cerebral cortex were 681 dissected out of the left hemisphere and flash-frozen for biochemical analysis. The other halves 682 were post-fixed in $4 \%$ paraformaldehyde, cryoprotected in $30 \%$ sucrose, and cut at $40 \mu \mathrm{m}$ on a 683 sliding vibratome for immunohistochemistry (IHC). Sections were rinsed three times and placed 684 in blocking buffer for $1 \mathrm{hr}$ (PBS, $0.02 \%$ Triton X-100, 5\% goat serum), and primary antibodies 685 placed in block overnight $(\mathrm{ON})$ at $4^{\circ} \mathrm{C}$. Sections were rinsed, incubated for $1 \mathrm{hr}$ in Alexa Fluor 686 secondary antibodies, and mounted using Fluoromount G (Southern Biotechnology). Primary 687 antibodies used include: Anti-Ki67 (Abcam, ab16667), Anti-Ku80 (Abcam, ab80592), Anti688 Nestin (Millipore Sigma, MAB5326), Anti-GFAP (Abcam, ab4674), Anti-DCX (Fisher Millipore, 689 AB2253MI), Anti-NeuN (Abcam, ab177487), Anti-Calretinin (Abcam, ab16694), Anti-vGlut1 690 (Abcam, ab180188), Anti-HNA (Abcam, ab191181), Anti-GAD65/67 (Abcam, ab49832), Anti691 BetaIII tubulin (Abcam, ab78078), Anti-DARPP32 (Abcam, ab40802), Anti-Ctip2 (Abcam, 692 ab233713). For IHC a minimum of four mice per group were analyzed. DAB staining for ChAT:

693 Sections were rinsed three times then 30 min in $3 \% \mathrm{H}_{2} \mathrm{O}_{2}$ and $10 \%$ Methanol rinsed and placed in 694 blocking buffer for $1 \mathrm{hr}(\mathrm{TBS}+5 \%$ normal rabbit serum (NBS Vector S-5000) + 0.1\% TritonX695 100), then primary antibody (goat anti-ChAT 9 Millipore AB144P) placed in block overnight at $6964^{\circ} \mathrm{C}$. Sections were rinsed, incubated for $1 \mathrm{hr}$ in secondary antibody (rabbit anti-goat biotinylated 697 secondary), incubated in ABC solution (Vector PK-6100) for $1 \mathrm{hr}$ at RT then 1-3min in DAB, 
698 rinse and mount tissue on slide. Confocal Microscopy: Sections were imaged with Bio-Rad

699 Radiance 2100 confocal system using lambda-strobing mode. Images represent either single

700 confocal z-slices or z-stacks. Whole cell tissue lysis: Lysis was performed in RIPA buffer

701 supplemented with protease inhibitors (Complete Mini, Roche Applied Science), 0.1 mM PMSF,

$70225 \mathrm{mM}$ NEM, $1.5 \mathrm{mM}$ aprotinin, and $23.4 \mathrm{mM}$ leupeptin by douncing then sonicated for 10

703 seconds, 3 times at $40 \%$ amplitude on ice. Samples were quantified using Lowry protein assay.

704 Soluble/Insoluble Fractionation: Striatal tissue was processed as described previously (Ochaba et

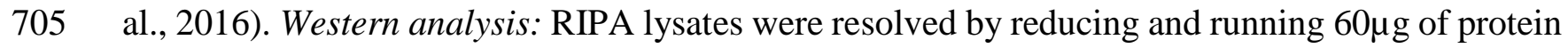

706 on 4-12\% Bis-Tris Poly-Acrylamide gels (PAGE). Antibodies: Anti-BDNF (Santa Cruz

707 Biotechnology, clone N-20, for mature BDNF, cat.no.sc-546), Anti-ERK (Cell Signaling

708 Technology, cat.no. 9102), Anti-pERK (Cell Signaling Technology, cat.no. 9106), Anti-alpha

709 tubulin (Sigma-Aldrich, cat.no. T6074). Quantification of bands was performed using software

710 from the NIH program ImageJ and densitometry application. 50 $\mu \mathrm{g}$ of reduced, insoluble protein

711 from Insoluble Fractions were resolved on 3-8\% Tris-Acetate Poly-Acrylamide gels. Membranes

712 were blocked in Starting block (Invitrogen) for 20 minutes at room temperature and probed in

713 primary antibody overnight at $4^{\circ} \mathrm{C}$. Insoluble protein was quantified as relative protein abundance

714 as previous (Ochaba et al., 2016). Antibodies: Anti-HTT (Millipore, \#MAB5492;

715 RRID: AB_347723).

717 Behavioral Tests: Males and females were used except for the running wheel, where only males

718 were used since estrus cycle influences running activity. Genotypes or treatments were unknown

719 to the experimenter. All tests were done during the light phase except for the running wheel, where

720 mice were allowed $24 \mathrm{hr}$ free access to the task. Running wheel data are only described for the 
721 dark phase. Slope of motor learning was calculated as mean nightly running wheel rotations per 3

722 minutes on night 5 minus night 2 divided by total number of nights (3) for initial and night 13

723 minus night 2 divided by total number of nights (11) for overall. Behavioral tasks, running wheel

724 and open field, were performed in a manner to those previously described (Hickey et al., 2008;

725 Reidling et al., 2018).

727 Electrophysiology: For electrophysiological studies we used 12 female mice (10.5 month-old)

728 shipped live to UCLA from UCI. Groups included: 4 zQ175 Het hNSC, 4 zQ175 Het vehicle, 2

729 WT hNSC, 2 WT vehicle. Mice were anesthetized and transcardially perfused with high sucrose-

730 based slicing solution. Coronal slices $(300 \mu \mathrm{m})$ were transferred to an incubating chamber

731 containing standard artificial cerebrospinal fluid (ACSF). MSNs and hNSCs were visualized using

732 infrared illumination with differential interference contrast optics (IR-DIC). All recordings were

733 performed in or around the injection site (recorded MSNs were adjacent to the graft, $\sim 150-250$

$734 \mu \mathrm{m})$. Biocytin $(0.2 \%)$ was added to the patch pipette for cell visualization and location of recorded

735 cells. Spontaneous postsynaptic currents were recorded in the whole-cell patch clamp

736 configuration in ACSF. Membrane currents were recorded in gap-free mode. Cells were voltage-

737 clamped at $+10 \mathrm{mV}$ and spontaneous inhibitory postsynaptic currents (sIPSCs) were recorded in

738 ACSF. Spontaneous excitatory postsynaptic currents (sEPSCs) from grafted cells were recorded

739 in ACSF at $-70 \mathrm{mV}$ (baseline). sEPSCs from MSNs, were recorded in the presence of the GABA

740 receptor blocker, bicuculline methobromide (BIC, $10 \mu \mathrm{M}$, Tocris, Minneapolis, MN) to better

741 isolate glutamatergic events. Spontaneous synaptic currents were analyzed using the MiniAnalysis

742 software (version 6.0, Synaptosoft, Fort Lee, NJ). To evoke responses in grafted cells, we used a

743 monopolar glass electrode (impedance $1 \mathrm{M} \Omega$ ) which was placed 200-300 $\mu$ m lateral to the graft. 
744 Following recordings, slices were fixed with 4\% PFA, then transferred to $30 \%$ sucrose at $4^{\circ} \mathrm{C}$ until

745 IHC processing. To identify biocytin-filled recorded cells and hNSCs, fixed slices were washed,

746 permeabilized with triton $(0.7 \%)$ and blocked for $4 \mathrm{~h}$, followed by incubation with SC121 (1:1000).

747 After washing, slices were incubated in goat, anti-mouse Alexa-488 (1:1000, Life Technologies,

748 Carlsbad, CA Catalog \#:A-11001) and streptavidin conjugated with Alexa-594 (1:1000, Life

749 Technologies Catalog \#: S11227). Slices were washed, mounted, and cells visualized with a Zeiss

750 Apotome confocal microscope.

752 Electron Microscopy (EM): Female zQ175 mice implanted with hNSCs for 8 months (n=3 per 753 group) at UCI were sent live to the Portland VA Medical Center. Mice were anesthetized and 754 perfused with EM fixative (2.5\% glutaraldehyde, $0.5 \%$ paraformaldehyde, and $0.1 \%$ picric acid in 755 0.1 M phosphate buffer [pH 7.4]). Brains were then collected and further processed in a Pelco 756 Biowave Pro+ (Ted Pella, Inc, Redding, CA), as previously reported (Moore et al., 2020), and then

757 washed in PBS and stored overnight at $4^{\circ} \mathrm{C}$. Striatum containing hNSCs (equivalent to +1.4 to $758+0.14 \mathrm{~mm}$ from Bregma) (Franklin and Paxinos, 2007) was cut at $60 \mu \mathrm{m}$ using a vibratome (Leica 759 Microsystems). After pre-embed IHC of the striatum using diaminobenzidine (DAB) (Sigma, St 760 Louis, MO) or ImmPACT® VIP Substrate, Peroxidase (HRP) (Cat \#: SK-4605)(Vector Labs, 761 Burlingame, CA), hNSC antibody (SC121, 1:100; Takara: Cat \#: Y40410) and vGlut 1 (vesicular 762 glutamate transporter 1) antibody (1:000; Synaptic Systems, Germany, Cat \#: 135-303), the tissue 763 was processed for EM as previously described (Walker et al., 2012; Parievsky et al., 2017; Reidling 764 et al., 2018; Moore et al., 2020). Two striatal slices were selectively double labeled for SC121 765 (DAB) and vGlut1(VIP) to determine if vGlut1 labeled terminals originating from the cortex 766 (Kaneko et al., 2002) innervated the implantation site. Striatal slices were embedded flat between 
767 two sheets of ACLAR (Electron Microscopy Sciences, Hatfield, PA) overnight in a $60^{\circ} \mathrm{C}$ oven to

768 polymerize the resin. The area containing hNSCs was micro-dissected from the embedded slice

769 and superglued onto a block for thin sectioning. Photographs were taken on a JEOL 1400

770 transmission electron microscope (JEOL, Peabody, MA) of DAB labeled structures (i.e., SC121)

771 and for a small number of sections, double labeled with DAB (SC121) and VIP (vGlut1)-labeled

772 structures (i.e., hNSC-labeled cells, dendrites, nerve terminals). The DAB labeled structures (i.e.,

773 SC121) were photographed both within and located $\sim 0.25 \mathrm{~mm}$ outside of the implantation zone,

774 at a final magnification of 46,200 using a digital camera (AMT, Danvers, MA). Since the DAB

775 and DAB/VIP labeling was restricted to the leading edge of the thin-sectioned tissue, only the area

776 showing DAB and DAB/VIP labeling was photographed. The percentage of SC121/DAB-labeled

777 asymmetrical and symmetrical synaptic contacts onto dendrites and spines within and outside the

778 implant area was quantified.

780 Statistical Analysis: Results are from a single cohort except for Western blots for BDNF and

$781 \mathrm{pERK/ERK}$ and IHC for ChAT, which were from a different subset. Numbers were determined to

782 have sufficient power using an analysis prior to the study. Assessment of differences in outcome

783 were based upon previous experience and published results (Hockly et al., 2003; Hickey et al.,

784 2005) for HD models, and applying power analysis (G Power [http://www.psycho.uni-

785 duesseldorf.de/abteilungen/aap/gpower3/]) led us to a minimal $n=5$ for behavior and $n=3$ for

786 biochemical analysis. Statistical significance was achieved as described using rigorous analysis.

787 All findings are reproducible. Experiments were performed at least 3 times using at least 3 different

788 mice (biological replicates) and in specific cases tissue from one mouse was used multiple times

789 (technical replicates); for example, in IHC at least 3 different mouse brains were used and multiple 
790 sections from each brain were examined to obtain data. Multiple statistical methods are further

791 detailed above, in figure legends, or in Supplementary Experimental Procedures. Since the EM

792 data are based on 3 implanted zQ175 mice, and not comparing them against the WT mice, the

793 percentages reported are a comparison within a single group of 3 experimental mice, therefore,

794 there was no statistical comparison. Statistical tests for behavioral tasks used one-way ANOVA

795 followed by Tukey's HSD test with Scheffé, Bonferroni, and Holm multiple comparison post hoc

796 methods. Data met the assumptions of the statistical tests used, and p values $<0.05$ were considered

797 significant. All mice were randomly assigned and tasks performed in a random manner with

798 individuals blinded to genotypes and treatment. Statistical comparisons of densitometry results

799 were performed by one-way ANOVA followed by Tukey HSD and Bonferroni post hoc tests. For

800 electrophysiology data, all statistical analyses were performed using SigmaPlot 13.0 software.

801 Differences between multiple group means were assessed with appropriate one-way ANOVAs

802 followed by Bonferroni post hoc tests, Kruskal-Wallis one-way ANOVA on ranks followed by

803 Holm-Sidak post hoc tests or Student's $t$-tests (unpaired) when only two groups were compared.

804 Significance levels in the figures are given as specific p-values and data are expressed as mean \pm

805 SEM.

806

807 Acknowledgments

808 Funding was provided by the California Institute for Regenerative Medicine (CIRM ETAII TR2-

809 01841), and NIH grants NS096994 and U54HD087101 (MSL).

810 We thank BioTime, Inc and AgeX for the ESI-017 cell line and the UC Davis Flow Cytometry

811 Shared Resource, 2921 Stockton Blvd., Suite 1300/1670 Sacramento, CA 95817 for flow analysis.

812 We also thank the UCI Institute for Memory Impairments and Neurological Disorders, the Sue and 
813 Bill Gross Stem Cell Center and the Optical Biology Shared Resource of the Cancer Center

814 Support Grant (CA-62203) at the University of California, Irvine for facilities and assistance in

815 carrying out studies.

816

817 Author contributions: J.C.R., S.M.H., C.C., M.S.L., L.M.T. designed experiments and analyzed

818 data. J.C.R., S.M.H., C.C., L.M.T., M.S.L. wrote the manuscript. S.Y., A.L., I.O. performed

819 experiments in mice, A.L. and M.N. did IHC and E.S.M. and J.C.R. performed analyses. S.M.H.,

820 C.C. performed electrophysiology and analyzed data with guidance from M.S.L. C.M. performed

821 EM with guidance from C.K.M. L.K. cultured hNSCs at UCI. B.F., D.C.-B. and G.B. supplied

822 ESI-017 hNSCs and characterizations from GMP facility at UCD.

823

824 Conflicts of interest: The authors declare they have no conflict of interest, financial or otherwise.

825 
bioRxiv preprint doi: https://doi.org/10.1101/2021.01.18.427078; this version posted January 19,2021. The copyright holder for this preprint (which was not certified by peer review) is the author/funder, who has granted bioRxiv a license to display the preprint in perpetuity. It is made available under aCC-BY 4.0 International license.

\section{Supplementary Figures}

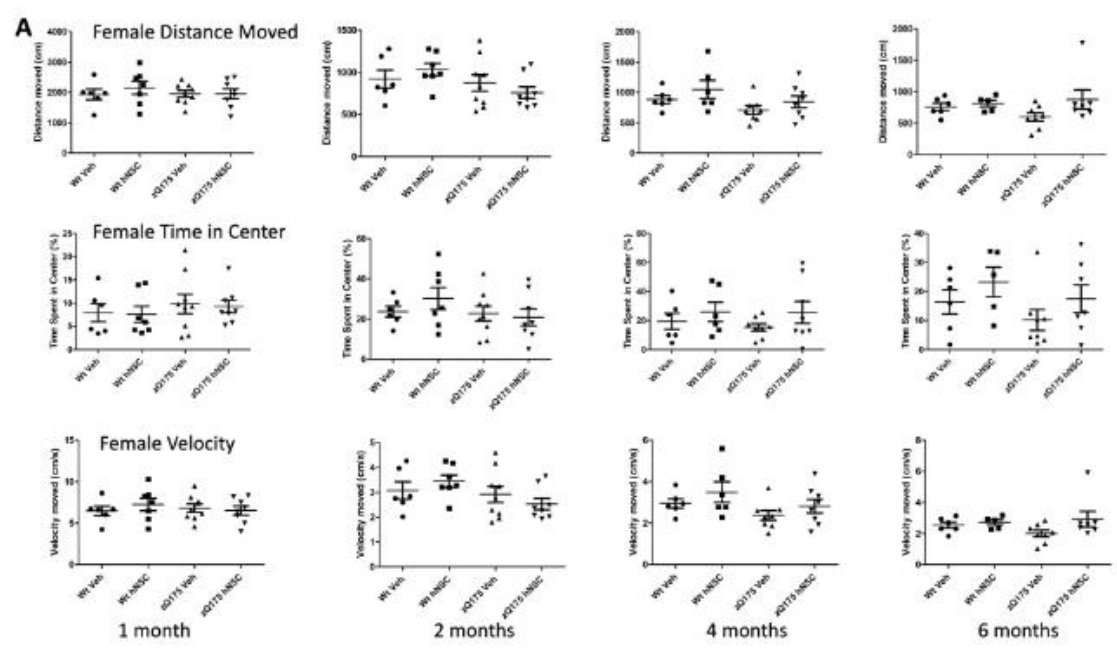

B ${ }^{\text {Male Distance Moved }}$

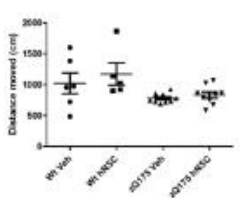

舟势

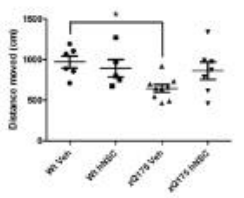

Male Time in Center

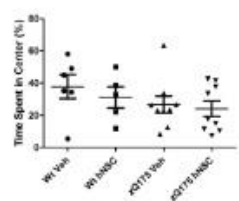

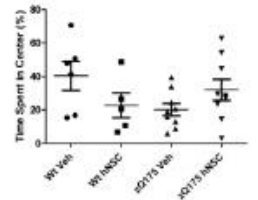

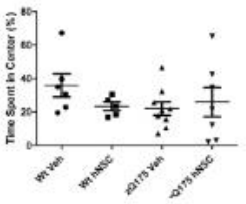

1 month

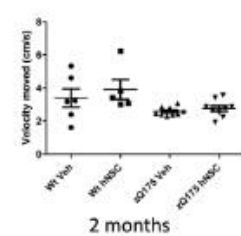

$\frac{1}{4 \text { months }}$

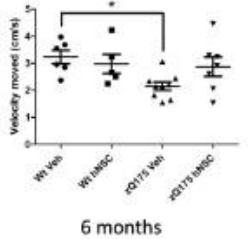

C
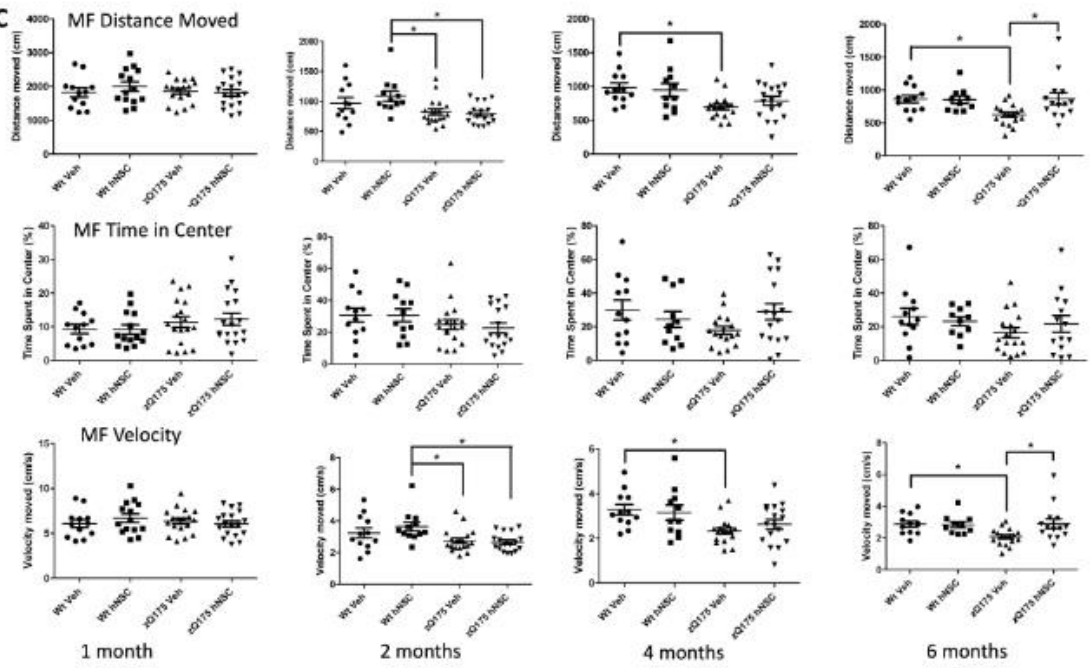

827 
Supp. Figure 1: Open Field behavior. Total distance traveled in the open field 6 months post implant. Mice were subjected to the open field and total distance in centimeters of their respective tracks were combined and statistically analyzed to visualize any differences in ambulation. Time spent in center was also measured. In addition, velocity traveled in centimeters/sec of their respective tracks were combined and statistically analyzed to visualize any differences in time of ambulation. A. Females B. Males and C. Males and Females combined. Groups for open field at 1 month included: 10 male zQ175 Het hNSC, 8 female Het hNSC, 9 male zQ175 Het veh, 9 female zQ175 Het veh, 7 male WT hNSC, 7 female WT hNSC, 6 male WT veh, 6 female WT veh. Groups for open field at 6 months included: 7 male zQ175 Het hNSC, 7 female Het hNSC, 9 male zQ175 Het veh, 8 female zQ175 Het veh, 5 male WT hNSC, 5 female WT hNSC, 6 male WT veh, 6 female WT veh. Results are expressed as the mean \pm S.E.M with one-way ANOVA Bonferroni post test: *In order of graphs $\mathrm{p}=0.03, \mathrm{p}=0.04, \mathrm{p}=0.03, \mathrm{p}=0.04, \mathrm{p}=0.01, \mathrm{p}=0.01, \mathrm{p}=0.01, \mathrm{p}=0.01$, $\mathrm{p}=0.01, \mathrm{p}=0.01$.
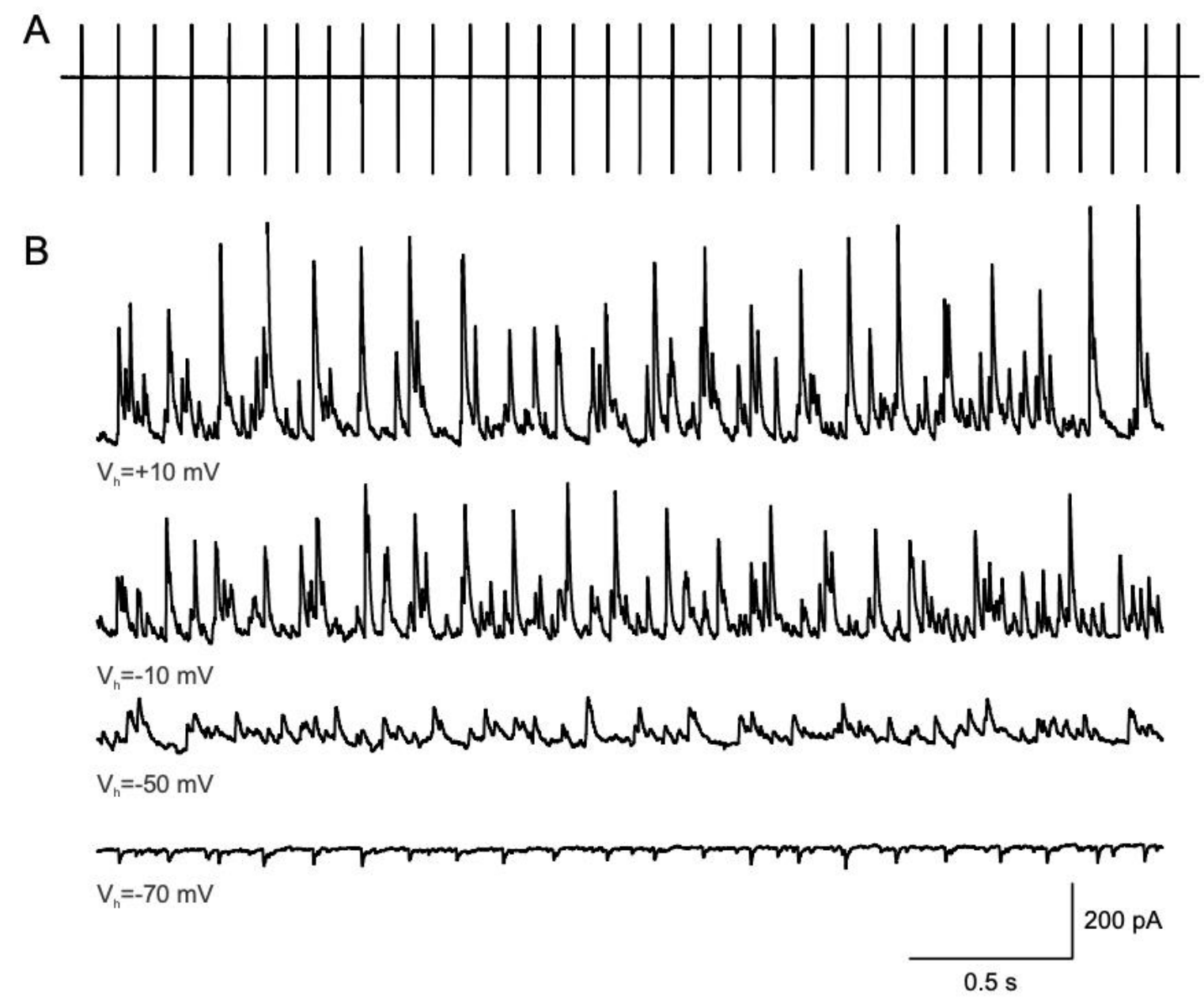

843 Suppl. Figure 2: hNSCs display rhythmic activities. A. In cell-attached mode this cell from a zQ175 mouse displayed autonomous, rhythmic firing activity. B. In voltage clamp mode, spontaneous, rhythmic synaptic events can be observed at different holding potentials (bottom 4 

conditions in striatal MSNs and this cell was assumed to be interneuron-like.
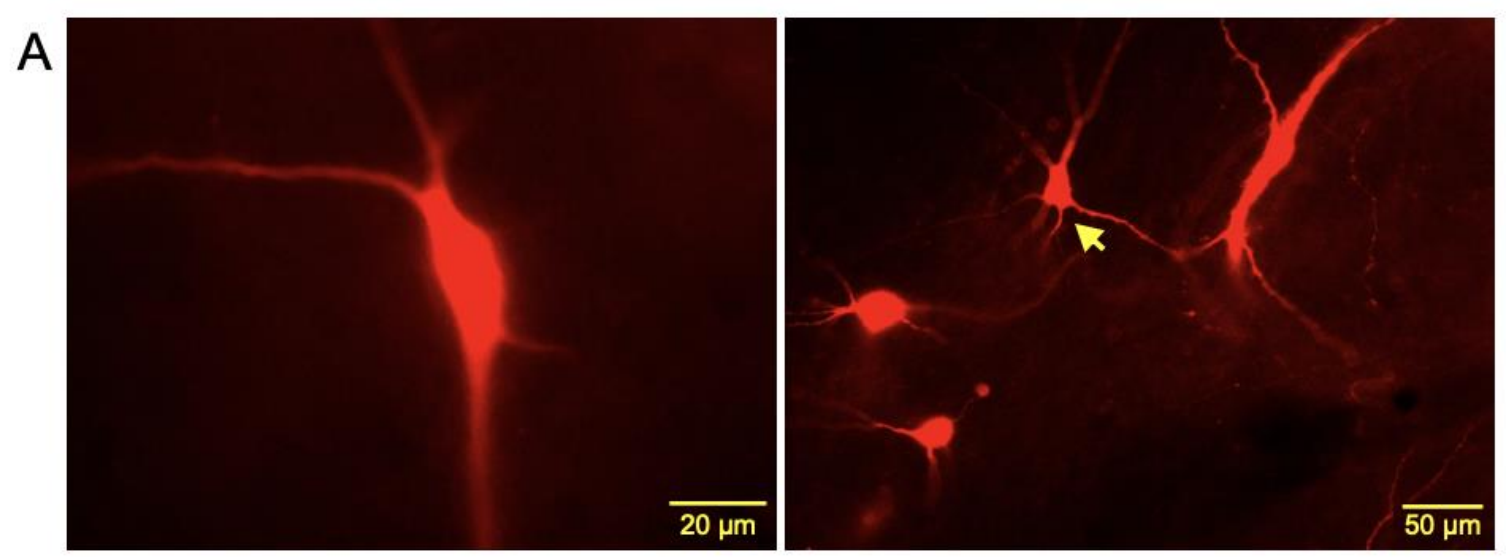

B
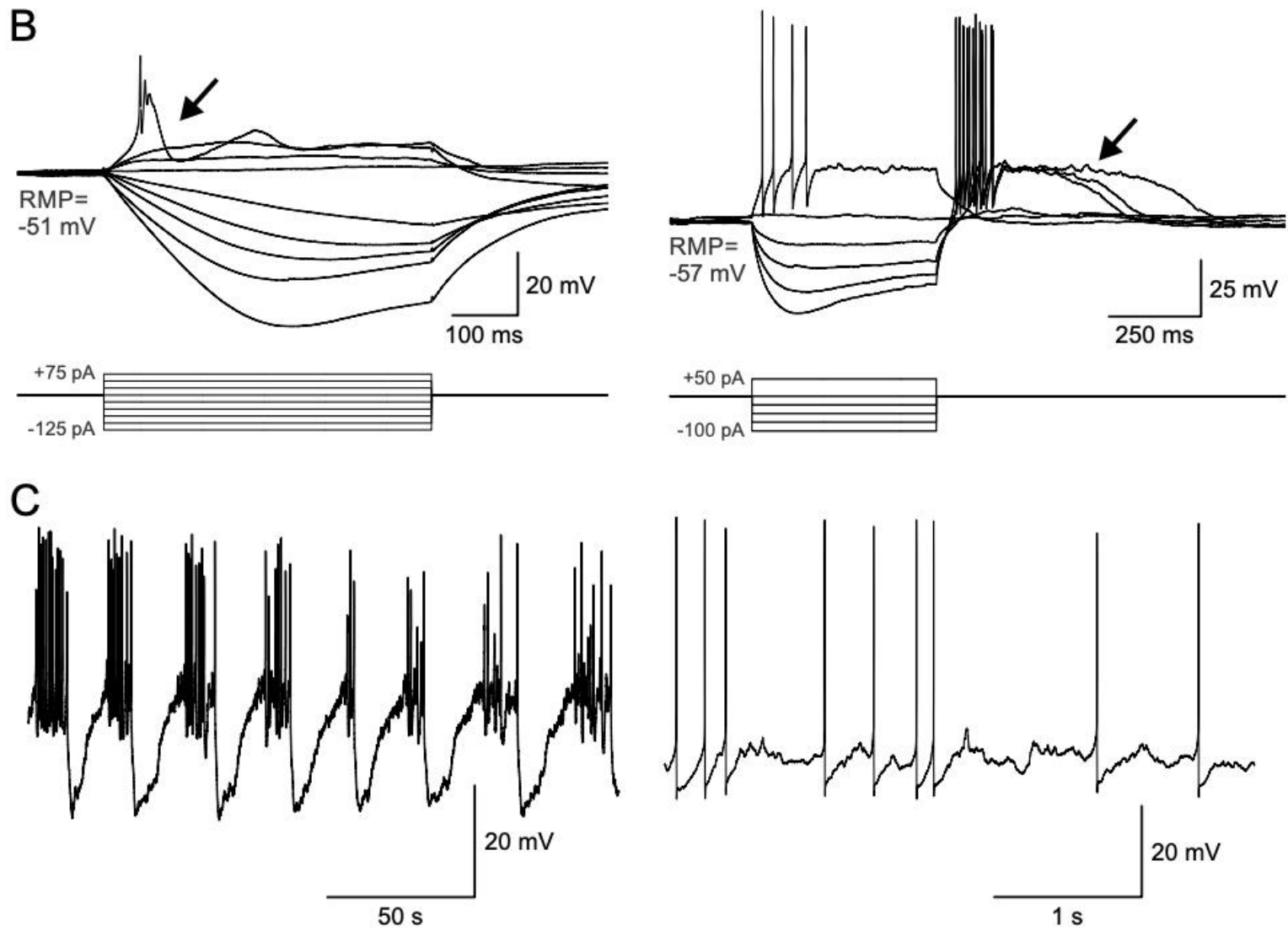

Suppl. Figure 3: A. Large hNSCs from two different zQ175 implanted mice were recorded and filled with biocytin. The hNSC on the left panel and the cell with the yellow arrow on the right panel displayed LTS-like interneuron properties. B. Traces are electrophysiological recordings in current clamp mode. Both cells displayed prominent inward rectification and lowthreshold $\mathrm{Ca}^{2+}$ spikes (arrows). C. Upon hyperpolarization by negative current injection the cell on the left displayed rhythmic membrane oscillations and bursts of action potentials. The 
bioRxiv preprint doi: https://doi.org/10.1101/2021.01.18.427078; this version posted January 19,2021. The copyright holder for this preprint (which was not certified by peer review) is the author/funder, who has granted bioRxiv a license to display the preprint in perpetuity. It is made available under aCC-BY 4.0 International license.

857 interneuron-like hNSC on the right displayed low-threshold $\mathrm{Ca}^{2+}$ spikes and fired spontaneously 858 at resting membrane potential $(-57 \mathrm{mV})$. Both cells shared similarities with striatal LTS 859 (somatostatin-expressing) interneurons.

860
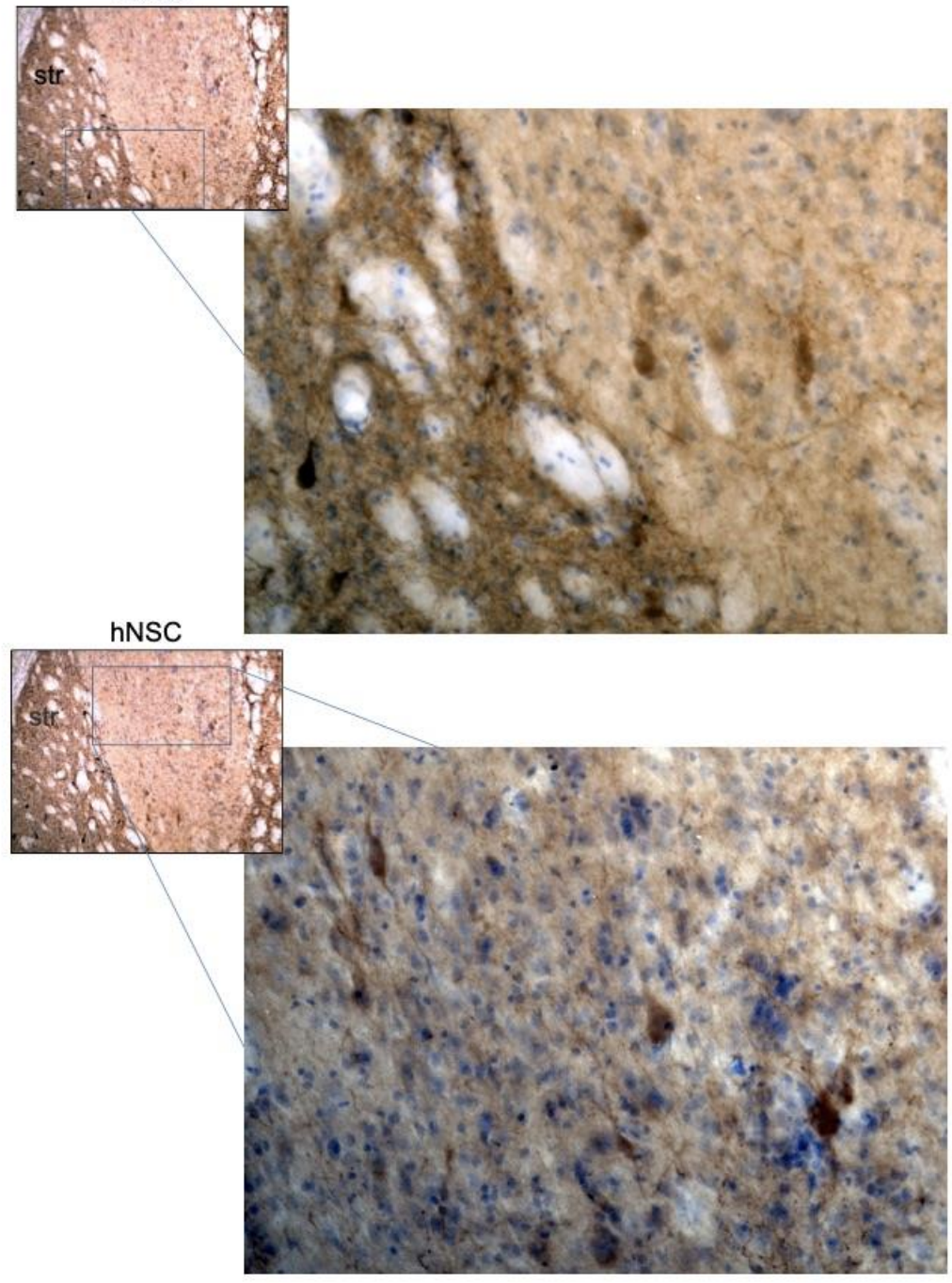

marker. 5x mag. of hNSCs in zQ175 showing overall implant site. 10X mag. then box indicating 20x mag. showing area in and around implant site that has DAB positive (brown) ChAT expressing cells.

866

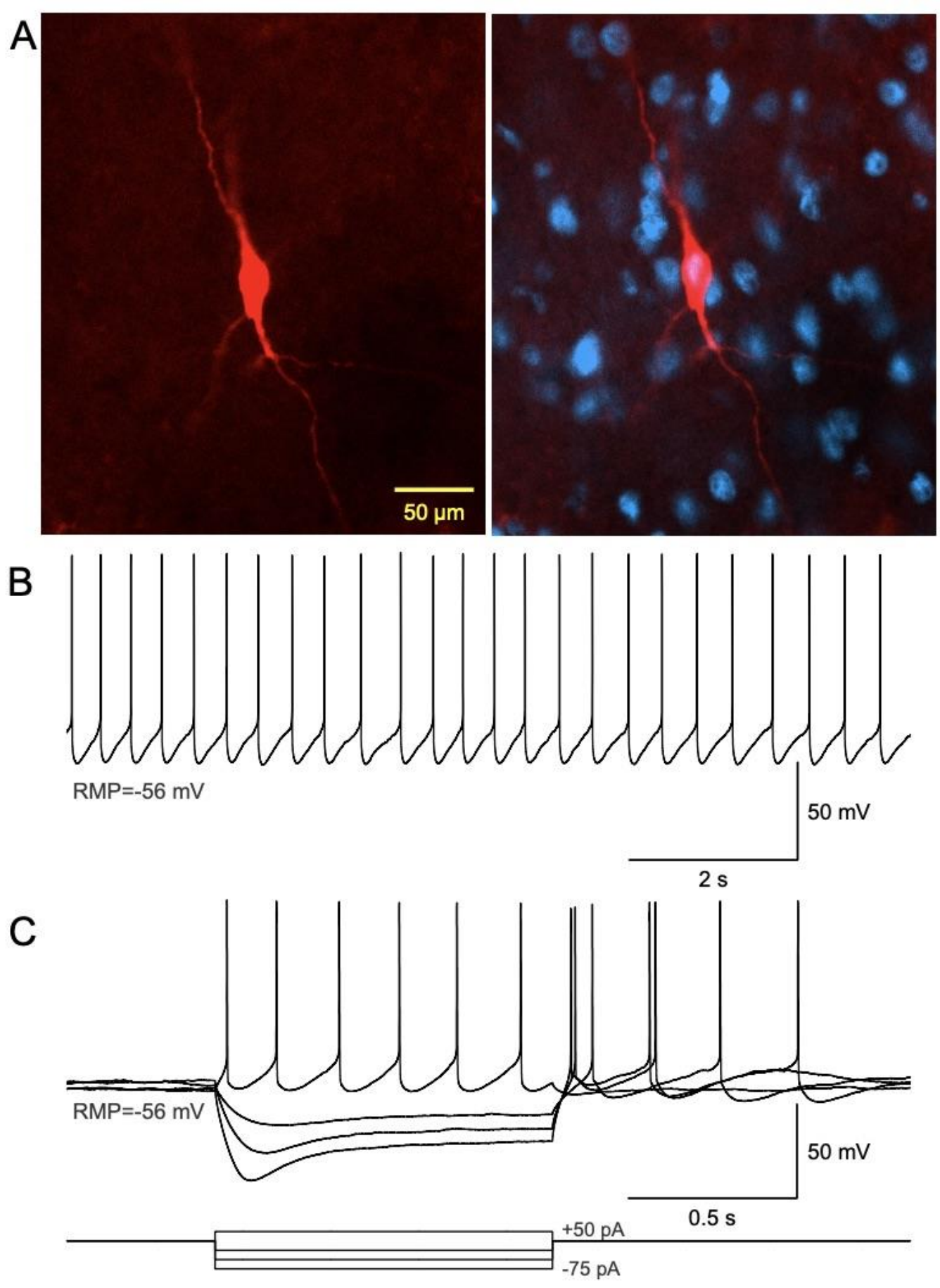


Suppl. Figure 5: A. Left panel shows a biocytin-filled, large hNSC. The right panel illustrates colocalization of the human marker Ku80 (blue) and biocytin (red). B. In current clamp mode, this

870 cell fired spontaneous, rhythmic action potentials (2-3 Hz), typical of striatal cholinergic 871 interneurons. C. Hyperpolarizing the cell also demonstrated delayed inward rectification, another 872 signature of striatal cholinergic interneurons.

873
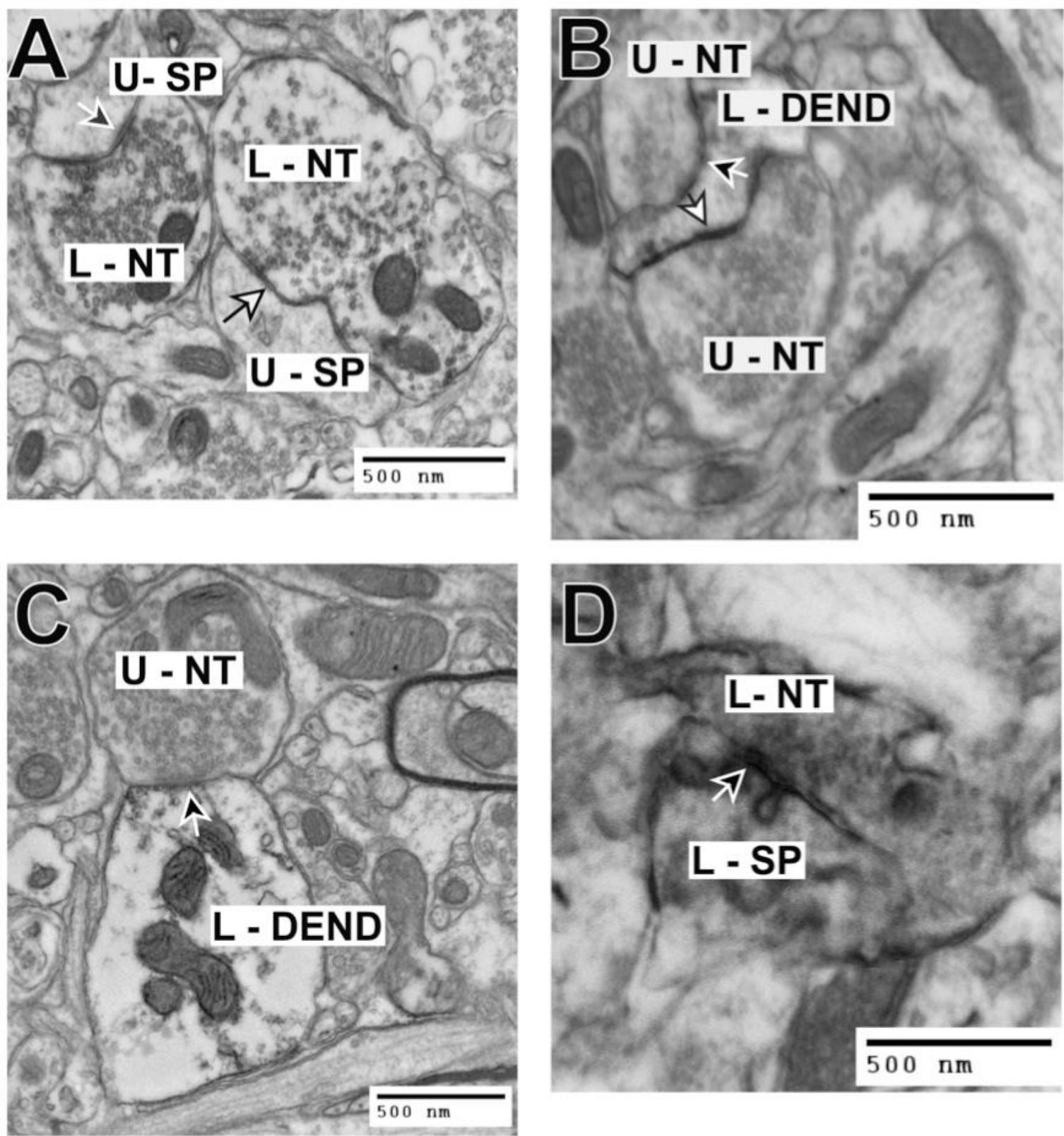

Suppl. Figure 6: Striatal synaptic contacts located outside the stem cell implantation zone. A. A labeled nerve terminal (L-NT) is making either an asymmetrical synaptic contact (black arrow with white outline) or a symmetrical contact (white arrow with black outline) with an underlying hNSC negative/unlabeled dendritic spine (U-SP)(note the darkened DAB reaction 
product within the nerve terminals). The hNSC labeled nerve terminals originate from the implanted stem cells, while the unlabeled dendritic spines originate from the host striatum. B. Unlabeled nerve terminals (U-NT) are making either an asymmetrical synaptic contact (black arrow with white outline) or a symmetrical contact (white arrow with black outline) with an underlying hNSC positive/labeled dendrite (L-DEN) (note the darkened DAB reaction product within the dendrite). The hNSC labeled dendrite originates from the implanted stem cells, while the unlabeled nerve terminals originate from the host striatum. C. Unlabeled nerve terminal (UNT) making an asymmetrical synaptic contact (arrow) with an underlying hNSC positive/labeled dendrite (L-DEND)(note the darkened DAB reaction product within the dendrite). The hNSC labeled dendrite originates from the implanted stem cells, while the unlabeled nerve terminal originates from the host striatum. D. Labeled nerve terminal (L-NT) is making a symmetrical synaptic contact (arrow) with an underlying hNSC positive/labeled dendritic spine (L-SP) (note the darkened DAB reaction product within the nerve terminal and spine). The hNSC labeled nerve terminal and dendritic spine originate from the implanted stem cells.

\section{References}

Bates G, Harper PS, Jones L (2002) Huntington's disease, 3rd Edition. Oxford ; New York: Oxford University Press.

Besusso D et al. (2020) Stem Cell-Derived Human Striatal Progenitors Innervate Striatal Targets and Alleviate Sensorimotor Deficit in a Rat Model of Huntington Disease. Stem cell reports.

Capetian P, Knoth R, Maciaczyk J, Pantazis G, Ditter M, Bokla L, Landwehrmeyer GB, Volk B, Nikkhah G (2009) Histological findings on fetal striatal grafts in a Huntington's disease patient early after transplantation. Neuroscience 160:661-675.

Cepeda C, Andre VM, Yamazaki I, Wu N, Kleiman-Weiner M, Levine MS (2008) Differential electrophysiological properties of dopamine D1 and D2 receptor-containing striatal medium-sized spiny neurons. Eur J Neurosci 27:671-682.

Cepeda C, Galvan L, Holley SM, Rao SP, Andre VM, Botelho EP, Chen JY, Watson JB, Deisseroth K, Levine MS (2013) Multiple sources of striatal inhibition are differentially affected in Huntington's disease mouse models. J Neurosci 33:7393-7406.

Choi KA, Hong S (2017) Induced neural stem cells as a means of treatment in Huntington's disease. Expert opinion on biological therapy 17:1333-1343.

Cicchetti F, Parent A (1996) Striatal interneurons in Huntington's disease: selective increase in the density of calretinin-immunoreactive medium-sized neurons. Mov Disord 11:619-626.

Connor B (2018) Concise Review: The Use of Stem Cells for Understanding and Treating Huntington's Disease. Stem cells 36:146-160.

Crook JM, Peura TT, Kravets L, Bosman AG, Buzzard JJ, Horne R, Hentze H, Dunn NR, Zweigerdt R, Chua F, Upshall A, Colman A (2007) The generation of six clinical-grade human embryonic stem cell lines. Cell stem cell 1:490-494.

Cummings DM, Andre VM, Uzgil BO, Gee SM, Fisher YE, Cepeda C, Levine MS (2009) Alterations in cortical excitation and inhibition in genetic mouse models of Huntington's disease. J Neurosci 29:10371-10386.

El-Akabawy G, Rattray I, Johansson SM, Gale R, Bates G, Modo M (2012) Implantation of undifferentiated and pre-differentiated human neural stem cells in the R6/2 transgenic mouse model of Huntington's disease. BMC Neurosci 13:97. 
Franklin KBJ, Paxinos G (2007) The Mouse Brain in Stereotaxic Coordinates, 3rd Edition: Academic Press.

Gertler TS, Chan CS, Surmeier DJ (2008) Dichotomous anatomical properties of adult striatal medium spiny neurons. J Neurosci 28:10814-10824.

Ghosh R, Tabrizi SJ (2018) Huntington disease. Handbook of clinical neurology 147:255-278.

Goldberg NRS, Marsh SE, Ochaba J, Shelley BC, Davtyan H, Thompson LM, Steffan JS, Svendsen CN, Blurton-Jones M (2017) Human Neural Progenitor Transplantation Rescues Behavior and Reduces alpha-Synuclein in a Transgenic Model of Dementia with Lewy Bodies. Stem Cells Transl Med 6:1477-1490.

Harper PS, Jones L (2002) Huntington's disease: Genetic and molecular studies. In: Huntington's Disease, Third Edition (Bates GP, Harper PS, Jones L, eds), pp 113-158. Oxford: Oxford University Press.

Heikkinen T, Lehtimaki K, Vartiainen N, Puolivali J, Hendricks SJ, Glaser JR, Bradaia A, Wadel K, Touller C, Kontkanen O, Yrjanheikki JM, Buisson B, Howland D, Beaumont V, MunozSanjuan I, Park LC (2012) Characterization of neurophysiological and behavioral changes, MRI brain volumetry and 1H MRS in zQ175 knock-in mouse model of Huntington's disease. PLoS One 7:e50717.

Hickey MA, Gallant K, Gross GG, Levine MS, Chesselet MF (2005) Early behavioral deficits in R6/2 mice suitable for use in preclinical drug testing. Neurobiol Dis 20:1-11.

Hickey MA, Kosmalska A, Enayati J, Cohen R, Zeitlin S, Levine MS, Chesselet MF (2008) Extensive early motor and non-motor behavioral deficits are followed by striatal neuronal loss in knock-in Huntington's disease mice. Neuroscience 157:280-295.

Hockly E, Woodman B, Mahal A, Lewis CM, Bates G (2003) Standardization and statistical approaches to therapeutic trials in the R6/2 mouse. Brain Res Bull 61:469-479.

Holley SM, Galvan L, Kamdjou T, Cepeda C, Levine MS (2019a) Striatal GABAergic interneuron dysfunction in the Q175 mouse model of Huntington's disease. Eur J Neurosci 49:79-93.

Holley SM, Galvan L, Kamdjou T, Dong A, Levine MS, Cepeda C (2019b) Major Contribution of Somatostatin-Expressing Interneurons and Cannabinoid Receptors to Increased GABA Synaptic Activity in the Striatum of Huntington's Disease Mice. Frontiers in synaptic neuroscience 11:14.

Holley SM, Joshi PR, Parievsky A, Galvan L, Chen JY, Fisher YE, Huynh MN, Cepeda C, Levine MS (2015) Enhanced GABAergic Inputs Contribute to Functional Alterations of Cholinergic Interneurons in the R6/2 Mouse Model of Huntington's Disease. ENEURO:0008-0014.

Holley SM, Kamdjou T, Reidling JC, Fury B, Coleal-Bergum D, Bauer G, Thompson LM, Levine MS, Cepeda C (2018) Therapeutic effects of stem cells in rodent models of Huntington's disease: Review and electrophysiological findings. CNS Neurosci Ther 24:329-342.

Indersmitten T, Tran CH, Cepeda C, Levine MS (2015) Altered excitatory and inhibitory inputs to striatal medium-sized spiny neurons and cortical pyramidal neurons in the Q175 mouse model of Huntington's disease. J Neurophysiol 113:2953-2966.

Jia N, Chong J, Sun L (2020) Application of stem cell biology in treating neurodegenerative diseases. The International journal of neuroscience:1-11.

Kaneko T, Fujiyama F, Hioki H (2002) Immunohistochemical localization of candidates for vesicular glutamate transporters in the rat brain. J Comp Neurol 444:39-62.

Kim TW, Koo SY, Studer L (2020) Pluripotent Stem Cell Therapies for Parkinson Disease: Present Challenges and Future Opportunities. Front Cell Dev Biol 8:729. 
971

972

973

974

975

976

977

978

979

980

981

982

983

984

985

986

987

988

989

990

991

992

993

994

995

996

997

998

999

1000

1001

1002

1003

1004

1005

1006

1007

1008

1009

1010

1011

1012

1013

1014

1015

1016

Kumar U (2008) Somatostatin in medium-sized aspiny interneurons of striatum is responsible for their preservation in quinolinic acid and N-methyl-D-asparate-induced neurotoxicity. J Mol Neurosci 35:345-354.

Mangiarini L, Sathasivam K, Seller M, Cozens B, Harper A, Hetherington C, Lawton M, Trottier Y, Lehrach H, Davies SW, Bates GP (1996) Exon 1 of the HD gene with an expanded CAG repeat is sufficient to cause a progressive neurological phenotype in transgenic mice. Cell 87:493-506.

Menalled LB, Kudwa AE, Miller S, Fitzpatrick J, Watson-Johnson J, Keating N, Ruiz M, Mushlin R, Alosio W, McConnell K, Connor D, Murphy C, Oakeshott S, Kwan M, Beltran J, Ghavami A, Brunner D, Park LC, Ramboz S, Howland D (2012) Comprehensive behavioral and molecular characterization of a new knock-in mouse model of Huntington's disease: $z Q 175$. PLoS One 7:e49838.

Moore C, Xu M, Bohlen JK, Meshul CK (2020) Differential ultrastructural alterations in the Vglut2 glutamatergic input to the substantia nigra pars compacta/pars reticulata following nigrostriatal dopamine loss in a progressive mouse model of Parkinson's disease. Eur J Neurosci.

Ochaba J, Monteys AM, O'Rourke JG, Reidling JC, Steffan JS, Davidson BL, Thompson LM (2016) PIAS1 Regulates Mutant Huntingtin Accumulation and Huntington's DiseaseAssociated Phenotypes In Vivo. Neuron 90:507-520.

Parievsky A, Moore C, Kamdjou T, Cepeda C, Meshul CK, Levine MS (2017) Differential electrophysiological and morphological alterations of thalamostriatal and corticostriatal projections in the R6/2 mouse model of Huntington's disease. Neurobiol Dis 108:29-44.

Plotkin JL, Day M, Peterson JD, Xie Z, Kress GJ, Rafalovich I, Kondapalli J, Gertler TS, Flajolet M, Greengard P, Stavarache M, Kaplitt MG, Rosinski J, Chan CS, Surmeier DJ (2014) Impaired TrkB receptor signaling underlies corticostriatal dysfunction in Huntington's disease. Neuron 83:178-188.

Qian H, Kang X, Hu J, Zhang D, Liang Z, Meng F, Zhang X, Xue Y, Maimon R, Dowdy SF, Devaraj NK, Zhou Z, Mobley WC, Cleveland DW, Fu XD (2020) Reversing a model of Parkinson's disease with in situ converted nigral neurons. Nature 582:550-556.

Reidling JC et al. (2018) Human Neural Stem Cell Transplantation Rescues Functional Deficits in R6/2 and Q140 Huntington's Disease Mice. Stem cell reports 10:58-72.

Reiner A, Shelby E, Wang H, Demarch Z, Deng Y, Guley NH, Hogg V, Roxburgh R, Tippett LJ, Waldvogel HJ, Faull RL (2013) Striatal parvalbuminergic neurons are lost in Huntington's disease: implications for dystonia. Mov Disord 28:1691-1699.

Saudou F, Humbert S (2016) The Biology of Huntingtin. Neuron 89:910-926.

Sepers MD, Smith-Dijak A, LeDue J, Kolodziejczyk K, Mackie K, Raymond LA (2018) Endocannabinoid-Specific Impairment in Synaptic Plasticity in Striatum of Huntington's Disease Mouse Model. J Neurosci 38:544-554.

Sivarajah S, Raj GS, Mathews AJ, Sahib NB, Hwang WS, Crook JM (2010) The generation of GLP-grade human embryonic stem cell banks from four clinical-grade cell lines for preclinical research. In vitro cellular \& developmental biology Animal 46:210-216.

Southwell AL, Smith-Dijak A, Kay C, Sepers M, Villanueva EB, Parsons MP, Xie Y, Anderson L, Felczak B, Waltl S, Ko S, Cheung D, Dal Cengio L, Slama R, Petoukhov E, Raymond LA, Hayden MR (2016) An enhanced Q175 knock-in mouse model of Huntington disease with higher mutant huntingtin levels and accelerated disease phenotypes. Hum Mol Genet 25:3654-3675. 
Tabrizi SJ, Ghosh R, Leavitt BR (2019) Huntingtin Lowering Strategies for Disease Modification in Huntington's Disease. Neuron 101:801-819.

Tepper JM, Koos T, Ibanez-Sandoval O, Tecuapetla F, Faust TW, Assous M (2018) Heterogeneity and Diversity of Striatal GABAergic Interneurons: Update 2018. Front Neuroanat 12:91.

The Huntington's Disease Collaborative Research Group (1993) A novel gene containing a trinucleotide repeat that is expanded and unstable on Huntington's disease chromosomes. Cell 72:971-983.

Vonsattel JP, DiFiglia M (1998) Huntington disease. J Neuropathol Exp Neurol 57:369-384.

Wagner L, Bjorkqvist M, Lundh SH, Wolf R, Borgel A, Schlenzig D, Ludwig HH, Rahfeld JU, Leavitt B, Demuth HU, Petersen A, von Horsten S (2016) Neuropeptide Y (NPY) in cerebrospinal fluid from patients with Huntington's Disease: increased NPY levels and differential degradation of the NPY1-30 fragment. J Neurochem 137:820-837.

Waldvogel HJ, Kim EH, Tippett LJ, Vonsattel JP, Faull RL (2015) The Neuropathology of Huntington's Disease. Current topics in behavioral neurosciences 22:33-80.

Walker RH, Moore C, Davies G, Dirling LB, Koch RJ, Meshul CK (2012) Effects of subthalamic nucleus lesions and stimulation upon corticostriatal afferents in the 6-hydroxydopaminelesioned rat. PLoS One 7:e32919.

Wu Z, Parry M, Hou XY, Liu MH, Wang H, Cain R, Pei ZF, Chen YC, Guo ZY, Abhijeet S, Chen $\mathrm{G}$ (2020) Gene therapy conversion of striatal astrocytes into GABAergic neurons in mouse models of Huntington's disease. Nature communications 11:1105.

Yoon Y, Kim HS, Hong CP, Li E, Jeon I, Park HJ, Lee N, Pei Z, Song J (2020) Neural Transplants From Human Induced Pluripotent Stem Cells Rescue the Pathology and Behavioral Defects in a Rodent Model of Huntington's Disease. Frontiers in neuroscience 14:558204. 